\title{
Modelling subsurface storm flow with the Representative Elementary Watershed (REW) approach: application to the Alzette River Basin
}

\author{
G. P. Zhang ${ }^{1,{ }^{*}}$, H. H. G. Savenije ${ }^{1}$, F. Fenicia ${ }^{1,2}$, and L. Pfister ${ }^{2}$ \\ ${ }^{1}$ Water Resources Section, Faculty of Civil Engineering and Geosciences, Delft University of Technology, Delft, The \\ Netherlands \\ ${ }^{2}$ Centre de Recherche Public - Gabriel Lippmann, Luxembourg, Grand-duchy of Luxembourg \\ *also at: Environment and Transportation, DHV B.V., Amersfoort, The Netherlands
}

Received: 1 December 2005 - Published in Hydrol. Earth Syst. Sci. Discuss.: 23 February 2006

Revised: 6 November 2006 - Accepted: 28 November 2006 - Published: 7 December 2006

\begin{abstract}
A new domain, the macropore domain describing subsurface storm flow, has been introduced to the Representative Elementary Watershed (REW) approach. The mass balance equations have been reformulated and the closure relations associated with subsurface storm flow have been developed. The model code, REWASH, has been revised accordingly. With the revised REWASH, a rainfall-runoff model has been built for the Hesperange catchment, a subcatchment of the Alzette River Basin. This meso-scale catchment is characterised by fast catchment response to precipitation, and subsurface storm flow is one of the dominant runoff generation processes. The model has been evaluated by a multi-criteria approach using both discharge and groundwater table data measured at various locations in the study site. It is demonstrated that subsurface storm flow contributes considerably to stream flow in the study area. Simulation results show that discharges measured along the main river course are well simulated and groundwater dynamics is well captured, suggesting that the model is a useful tool for catchment-scale hydrological analysis.
\end{abstract}

\section{Introduction}

Contributions of subsurface flow to storm runoff have long been recognised and investigated (Hewlett and Hibbert, 1965; Whipkey, 1967; Sklash and Farvolden, 1979; McDonnell, 1990; Uchida et al., 2002; Uhlenbrook et al., 2002, and references therein). The dominance of subsurface flow on hydrological response of catchments in humid areas is due to the high infiltration capacities of the forest soils and the

Correspondence to: G. P. Zhang

(g.zhang@tudelft.nl) limited extent of saturated source areas formed during precipitation events (e.g. Wigmosta and Burges, 1977; Tanaka et al., 1988; Scanlon et al., 2000). Sidle et al. (2000) stated that subsurface flow contributes more to storm runoff than overland flow in steep forested catchments.

The significance of research on subsurface flow is at least two-fold: 1) to enhance the understanding of hydrological behaviour at various level of scale (field, hillslope and catchment) due to the various pathways of flow; 2) and hence to improve the description of solute/contaminant transport in terrestrial environment. It is obvious that insight of hydrological processes in the subsurface must be understood before the quantification or qualification of pollutants movement can be addressed.

In contrast to soil matrix flow, there exist different terms for describing quick subsurface flow processes associated with the diversity of the flow paths in the soil. Examples are pipe flow, which is presented as the flow through well connected macropores found on vegetated hillslopes (Uchida et al., 2002, and the cited references therein) and macropore flow defined as quick movement of water in large pores bypassing areas with smaller pores (Williams et al., 2002). Considering the subjectivity of the term "macropore", bypass flow (e.g. Beven and Gemann, 1982) and preferential flow have been used as well. Wilson et al. (1990) concluded that in their study site, preferential flow through macropores is the predominant storm flow mechanism. The term interflow has been used as an intermediate form of runoff between surface and base flow which can be found through hydrograph separation (e.g. Mosley and McKerchar, 1993). Throughflow is perceived as the flow through a saturated or near-saturated zone in the subsurface induced by a permeability jump. Since some or all of the above mentioned processes can coexist in one area, especially at hillslope and watershed scale, and it

Published by Copernicus GmbH on behalf of the European Geosciences Union. 
is hard to specify flow paths and therefore to quantify contributions of each local process to storm runoff, we herein generalize all kinds of quick subsurface flow contributing to storm runoff as subsurface storm flow. It is the redistribution of infiltrated water in the soil along the slope of the terrain through macropore structures, fractures and discontinuity of permeability.

Although field experiments have already demonstrated that subsurface storm flow is an important fast runoff generation mechanism, most physically based model approaches or model codes, such as MIKE SHE (Refsgaard and Storm, 1995), GSSHA (Downer and Ogden, 2003), the REW approach (Reggiani et al., 2000; Reggiani and Rientjes, 2005), CREW (Lee at al., 2006) and REWASH (Zhang and Savenije, 2005), only use infiltration-excess and saturation-excess overland flow mechanisms for producing quick runoff. When applying such model codes to a catchment where subsurface storm flow is dominant, structural inefficiency of the models emerges. Despite the fact that McDonnell (2003) provoked a modelling philosophy on moving beyond the variable source area concept of rainfall-runoff response, it remains a challenge, as discussed by Sivapalan (2003), to develop a perceptual model that generalises field knowledge and assimilates it into a numerical model.

In spite of abundant research on modelling preferential flow at the field scale focusing on solute and contaminant transport, sparse literature exists on catchment-scale rainfallrunoff modelling accounting for subsurface storm flow process. Scanlon et al. (2000) made a modified version of TOPMODEL with an additional subsurface storage in line with the storage deficit concept to take the shallow subsurface storm flow into account and applied it to a 237 ha headwater catchment. Beckers and Alila (2004) evaluated contributions of subsurface storm runoff (termed as rapid preferential hillslope runoff) to peak flow at a $10 \mathrm{~km}^{2}$ forest watershed, using a model inclusive of both fast and slow preferential flow stores. They concluded that the model with preferential flow description is more successful in capturing stream flow behaviour of the studied catchment than the model without preferential flow process. Christiansen et al. (2004) presented a study on macropore flow and transport at a $62.3 \mathrm{~km}^{2}$ catchment applying MIKE-SHE/Daisy in which a macropore component is embedded. The formulation of macropore processes in their work was specifically designed for this particular catchment, considering only vertical flow from the macropore domain to the groundwater. Their results suggested, however, that macropore processes have no dominating effects on discharge at catchment scale. Zehe et al. (2001) carried out detailed simulations on a Loess catchment using CATFLOW in which the spatial distribution of the macroporosity factor was applied to treat the preferential flow process. Their approach yielded simulation results in good accordance with observations on both the plot and the hillslope scales.
To contribute to further development and application of the Representative Elementary Watershed (REW) approach, this paper has been designed to apply REWASH code (Zhang and Savenije, 2005) to the Hesperange catchment of the Alzette river basin, in Luxembourg. In this catchment subsurface storm flow is dominant. In the existing REW codes, catchment response is modelled by flow processes in five domains and fast runoff is simulated only by the surface overland flow mechanisms. Therefore, a new formulation for subsurface storm flow has been developed and an additional flow domain for rapid subsurface flow has been built into REWASH. In the following sections, this new model is described and tested. Results show that subsurface storm flow constitutes a considerable part of the stream flow in the upstream headwater sub-catchments. Model validation using a multi-criteria approach with interior gauging data and point piezometric measurements confirm the model's capability of successfully capturing the hydrological behaviour at catchment scale.

\section{Modelling approach}

\subsection{Brief review of the REW approach and the REWASH code}

The REW approach treats the entire catchment as an ensemble of a number of sub-catchments interconnected through the groundwater and a surface drainage network. The subcatchments, preserving the basic watershed functional components (hillslopes and channels) and having repetitive structure of the flow domains, are called representative elementary watersheds (REWs). Each sub-catchment or REW has a volume, which is defined by the topographic divide on top and an impermeable layer (if known) or a chosen depth at bottom. Originally, the flow processes are implemented over five flow domains within each REW, namely the infiltrationexcess flow domain, the saturation-excess flow domain, the river flow domain, the unsaturated and the saturated flow domains.

Starting from the basic physical laws (mass conservation and momentum balance), Reggiani et al. (1998, 1999) derived a system of ordinary differential equations at REW scale governing water flow in the five flow domains. Earlier publications (Reggiani et al., 2000, 2001; Reggiani and Rientjes, 2005; Zhang et al., 2005a; Zhang and Savenije, 2005) proposed a set of closure relations to the general form of the balance equations. Subsequently, new and revised equations for threshold-based interception, evaporation and transpiration, the Green-Ampt type infiltration, and Darcy type percolation etc., have been obtained, leading to the model code REWASH. Details of these equations can be found in Zhang and Savenije (2005).

REWASH has been applied to the Geer river basin in Belgium (Zhang and Savenije, 2005). While it is one of the early applications of the REW approach and demonstrates 
the approach's attractiveness, we argue that the very form of the approach does not warrant its universal applicability because hydrological processes are site-specific. However, the concept of the REW approach is open to any other processes to be included. To enhance the generality of the model code and to make it suitable for our study site, we extended REWASH by including the subsurface storm flow domain (which we shall term the macropore domain hereafter for reason of brevity) and developed an approach to quantifying the effect of subsurface storm flow on stream runoff.

\subsection{Approach to subsurface storm flow}

\subsubsection{Motivation of modelling subsurface storm flow}

Subsurface storm flow can significantly contribute to stream flow in many humid forested catchments (e.g. Wigmosta and Burges, 1977; Tanaka et al., 1988; Sidle et al., 2000). In the study catchment of the Alzette river basin, marls, schists and limestone are geologically dominant, and soils are usually shallow consisting of mainly loamy sand, loamy clay and silty loam (Pfister and Hoffmann, 2002). Field observations demonstrate the existence of well developed fractures and other preferential flow paths. Except during the very extreme events, runoff generation in these areas is dominated by subsurface storm runoff either by the so-called Transmissivity Feedback Mechanism (TFM, e.g., Bishop et al., 2004) or by downhill quick delivery of water through macropore structures. In addition, Zhang et al. (2005b) modelled the catchment response of the study area using the REWASH code with and without consideration of the subsurface storm flow process. That study, although a preliminary one, already showed that the model with subsurface storm flow gave much better results than the model without subsurface storm flow.

\subsubsection{Conceptualisation of subsurface storm flow}

Since subsurface storm flow may take a variety of paths, it is difficult to specify the exact dimensions of the spatial domain for this flow process at catchment scale, we conceptualise that the unsaturated soil profile (between surface and the groundwater table) hosts two process domains: the unsaturated flow domain where unsaturated flow takes place in the soil matrix, and the macropore domain, where preferential flow takes place. These process domains are located in one single zone: the unsaturated zone. Hence, the total volume of subsurface media of a REW is still composed of the unsaturated and the saturated zone.

With this conceptualisation, a dual-porosity approach is adopted for dealing with soil properties in modelling unsaturated and macropore flow, i.e., the total soil porosity of the unsaturated soil profile is made up by the soil porosity of the unsaturated domain and that of the macropore domain. The hydraulic conductivity for the macropore domain is higher than that for the unsaturated domain (e.g. Ludwig et al., 1999). In the unsaturated domain, only vertical flows are considered, as described in earlier publications on the REW approach. Although earlier research on preferential flow paths focused on vertical transport only, lateral flow is evident in steep forested slopes underlain by bedrock as discussed by Sidle et al. (2001). Therefore, both downward and lateral flows are accounted for in the macropore domain. As a result, the macropore domain is assumed to connect with the infiltration-excess overland flow domain, the saturated domain (groundwater) and the river channel, whereas the exchange between the unsaturated domain (soil matrix) and the macropore domain is neglected. Figure 1 represents the conceptual scheme of the new model for this study.

\subsubsection{Mass balance equations for the revised REWASH}

As a result of the introduction of subsurface storm flow in the macropore domain, flux exchanges and mass conservation in six domains have been reformulated for each REW. The momentum balance equations of the five existing domains, which serve as closure of the mass balance equations, will not be reformulated in this paper since most of them have already been presented in previous work. Only the revised mass balance equations of the six domains and the closure relation for the subsurface storm flow process will be presented in the following.

\section{Mass conservation for the infiltration-excess overland flow domain}

A domain is treated as a reservoir of which the water storage change is balanced by the incoming and outgoing water fluxes. For the infiltration-excess overland flow domain, these fluxes are the rainfall, the evaporation and the infiltration. The water balance is described as:

$\frac{\mathrm{d}\left(\rho y_{c} \omega_{c} A\right)}{\mathrm{d} t}=e_{\mathrm{ctop}}+e_{c a}+e_{c u}+e_{c m}$

On the left hand side of Eq. (1), $\rho\left[\mathrm{ML}^{-3}\right]$ is water density; $y_{c}[\mathrm{~L}]$ and $\omega_{c}[-]$ are the flow depth and the area fraction of the infiltration-excess overland flow domain, respectively. $\omega_{c}$ is assumed equal to the area fraction of the unsaturated domain $\omega_{u} . A\left[\mathrm{M}^{2}\right]$ is the planar area of the REW in question. On the right hand side of Eq. (1), $e_{\text {ctop }}\left[\mathrm{MT}^{-1}\right], e_{c a}\left[\mathrm{MT}^{-1}\right]$, and $e_{c u}\left[\mathrm{MT}^{-1}\right]$ are the rainfall on the surface of this domain, the evaporation from interception, the infiltration to the unsaturated soil matrix domain, respectively. $e_{c m}\left[\mathrm{MT}^{-1}\right]$ is the infiltration flux from this domain to the soil macropore domain.

\section{Mass conservation for the unsaturated domain}

Similarly, the storage of the unsaturated domain changes with the incoming and outgoing fluxes of the domain. The 


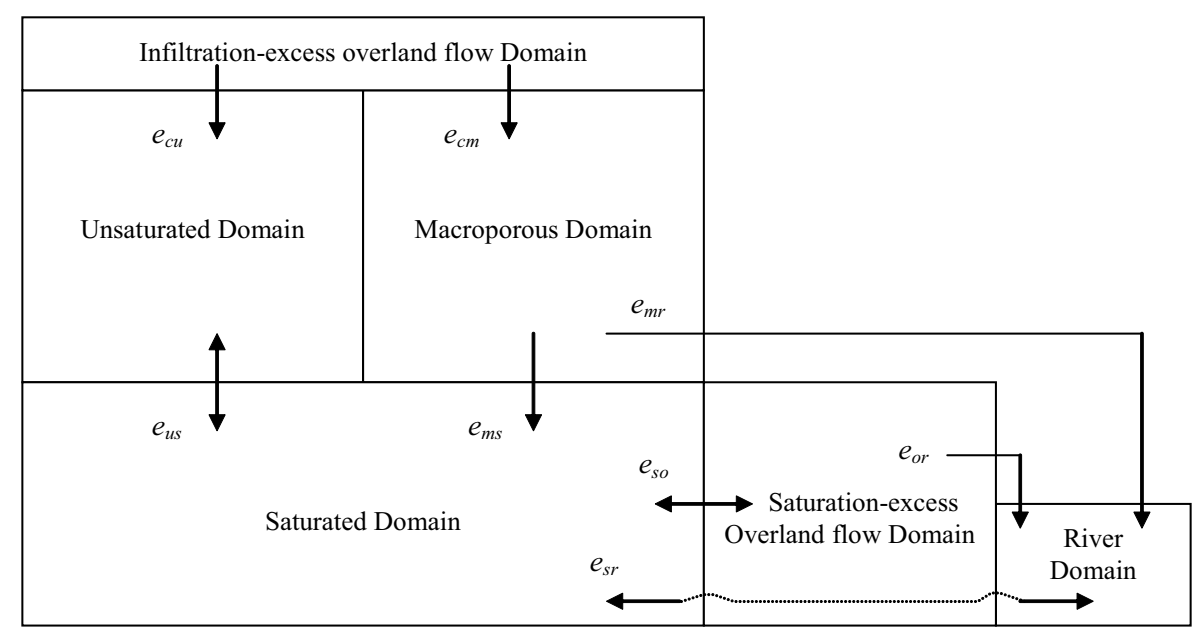

Fig. 1. Conceptual scheme of flow processes and relevant fluxes described in the revised REWASH. The boxes represent the reservoirs and the arrows are indicating the directions of the fluxes. $e_{c u}, e_{c m}$ are the infiltration fluxes to the unsaturated and the soil macropore domains, respectively. $e_{u s}$ is the percolation or capillary flux. $e_{m s}$ is the recharge flux from the macropore domain to the saturated domain. Self-explanatorily, the remaining symbols stand for various fluxes indicated by the letters, as also explained in the text.

balance equation reads:

$\frac{\mathrm{d}\left(\rho \varepsilon_{u} s_{u} y_{u} \omega_{u} A\right)}{\mathrm{d} t}=e_{u c}+e_{u s}+e_{u a}+e_{u m}$

where $\varepsilon_{u}[-]$ is the soil porosity of the unsaturated domain and $s_{u}[-]$ is the saturation degree of the unsaturated domain. $y_{u}$ is the average depth of the unsaturated domain and $\omega_{u}$ is the same as explained previously. $\rho$ and $A$ are the same as in Eq. (1), and the same in the following equations as well. $e_{u c}$ $\left[\mathrm{MT}^{-1}\right], e_{u s}\left[\mathrm{MT}^{-1}\right]$, and $e_{u a}\left[\mathrm{MT}^{-1}\right]$ are the infiltration, the percolation and the transpiration fluxes, respectively. $e_{u c}$ is the counterpart of $e_{c u}$ in Eq. (1), i.e. $e_{u c}=-e_{c u} . e_{u m}\left[\mathrm{MT}^{-1}\right]$ is the flux exchanging between the soil matrix and the macropore domain. In this study, this term is neglected. This is assumed with the consideration that the observations in the field of the catchment indicate that subsurface preferential flow is a major contributor to stream runoff and the process is so fast that the water exchange between the two domains is of minor effect on the runoff processes. As a first step to analyse the rainfall-runoff relation of this catchment with the REW approach, water quantity is our main concern in modelling, this assumption could be relaxed in the future without much difficulty, particularly if water quality and residence times are concerned. For instance, the method described in Niehoff et al. (2002) is one of the approaches that can be adopted to model the water exchange between the soil matrix and the macropores.

\section{Mass conservation for saturated domain}

The saturated domain exchanges water with the unsaturated domain, the macropore domain, the saturation-excess overland flow domain and the river channel domain. These ex- change fluxes counterbalance the storage change of the domain. The water balance is expressed by:

$$
\frac{\mathrm{d}\left(\rho \varepsilon_{s} y_{s} \omega_{s} A\right)}{\mathrm{d} t}=e_{s u}+e_{s o}+e_{s r}+e_{s m}
$$

where $\varepsilon_{s}[-]$ is the soil porosity of the saturated domain. Similar to Eq. (2), $y_{s}[-]$ and $\omega_{s}[-]$ are the average depth and the area fraction of the saturated domain, respectively. $e_{s u}$ $\left[\mathrm{MT}^{-1}\right]$ is the counterparts of $e_{u s}$ in Eq. (2) (i.e. $e_{s u}=-e_{u s}$ ) and $e_{s o}\left[\mathrm{MT}^{-1}\right]$ is the exfiltration flux towards the saturationexcess overland flow. $e_{s r}\left[\mathrm{MT}^{-1}\right]$ is the flux exchange with the river domain. $e_{s m}\left[\mathrm{MT}^{-1}\right]$ is the recharge flux to the saturated domain fed by the macropore domain

\section{Mass conservation for the macropore domain}

The storage capacity in the macropore domain is comprised of the porous space of the domain, represented by the macroporosity and the volume. The volume of the domain is the product of the average depth and the area of the domain. The processes occurring in the domain are the rainfall infiltration, the bypass flow to the groundwater (recharge), the lateral quick flow to the river channel, and water exchange with the unsaturated soil matrix. Evaporation and transpiration are ignored since the temporal scale of the flow processes in this domain is small compared to those in the slow flow domains. Consequently, the mass balance equation for the macropore domain reads:

$\frac{\mathrm{d}\left(\rho \varepsilon_{m} s_{m} y_{m} \omega_{m} A\right)}{\mathrm{d} t}=e_{m c}+e_{m r}+e_{m s}+e_{m u}$

where $\varepsilon_{m}[-]$ and $s_{m}[-]$ are the macroporosity and the saturation degree of the macropore domain respectively. $y_{m}$ 
[L] and $\omega_{m}[-]$ are the average depth and the area fraction of the macropore domain while $y_{m}$ is the same as $y_{u}$, as described above in the definition of the macropore domain. Macropores and other types of large openings are diffusively distributed in the subsurface and therefore it is difficulty to precisely locate the macropore structure and define its dimensions. Hence we assume that the structures facilitating quick subsurface flow are homogeneously distributed over the unsaturated soil profile, thus occupying the same area of the unsaturated domain, i.e. $\omega_{m}=\omega_{u} \cdot e_{m c}$ $\left[\mathrm{MT}^{-1}\right]\left(e_{m c}=-e_{c m}\right), e_{m r}\left[\mathrm{MT}^{-1}\right], e_{m s}\left[\mathrm{MT}^{-1}\right]\left(e_{m s}=-e_{s m}\right)$ and $e_{m u}\left[\mathrm{MT}^{-1}\right]\left(e_{m u}=-e_{u m}\right)$ are the infiltration from the infiltration-excess overland flow domain, the lateral flow from the macropore domain to the river channel the recharge flux to the saturated domain, and the exchange with the unsaturated domain, respectively. With the same reasoning as postulated for the processes of the unsaturated domain, the exchange flux between the macropore domain and the unsaturated soil matrix is neglected in this study.

\section{Mass conservation for the saturation-excess overland flow domain}

The water storage change of the saturation-excess overland flow domain is counterbalanced by the rainfall input, the evaporation flux, the water exchanges with the saturated domain and the river domain. As a result, the balance is in the form:

$$
\frac{\mathrm{d}\left(\rho y_{o} \omega_{o} A\right)}{\mathrm{d} t}=e_{\text {otop }}+e_{o a}+e_{o s}+e_{o r}
$$

where $y_{o}[\mathrm{~L}]$ and $\omega_{o}[-]$ are the average depth and the area fraction of the saturation-excess overland flow domain, respectively. $e_{\text {otop }}\left[\mathrm{MT}^{-1}\right], e_{o a}\left[\mathrm{MT}^{-1}\right], e_{o s}\left[\mathrm{MT}^{-1}\right]$ $\left(e_{o s}=-e_{s o}\right)$ and $e_{o r}\left[\mathrm{MT}^{-1}\right]$ are the rainfall on the surface of this domain, the open water evaporation flux, the exchange with the saturation-excess overland flow domain and overland flow to the river domain, respectively.

\section{Mass conservation for the river channel domain}

The fluxes entering and leaving the river domain of a REW consist of rainfall, evaporation, the lateral flow from the overland flow domain and the macropore domain, the baseflow from the saturated domain, the upstream channel inflow and the outflow to the downstream channel. Therefore, the storage change of the channel domain is determined by:

$$
\frac{\mathrm{d}\left(\rho m_{r} l_{r}\right)}{\mathrm{d} t}=e_{\text {rtop }}+e_{r a}+e_{r s}+e_{r o}+e_{r m}+e_{\text {rin }}+e_{\text {rout }}
$$

where $m_{r}\left[\mathrm{~L}^{2}\right]$ and $l_{r}[\mathrm{~L}]$ are the cross-sectional area and the channel length of the river under study, respectively. $e_{\mathrm{rtop}}$ $\left[\mathrm{MT}^{-1}\right]$ is the rainfall flux onto the river surface. $e_{r a}\left[\mathrm{MT}^{-1}\right]$ is the evaporation flux. $e_{r s}, e_{r m}$ and $e_{r o}$ are the counterparts of $e_{s r}, e_{m r}$ and $e_{o r}$ in Eqs. (3), (4) and (5), respectively.
2.2.4 Closure relations for fluxes in the mass conservation equations

To solve the balance equations presented above, each flux term has to be expressed by functions relating the unknowns to state variables and other fluxes. For most of the fluxes, these closure relations are the same as in previous publications on REWASH. In this paper, we only address those fluxes exchanging with the macropore domain, i.e. $e_{m c}$ $\left(=-e_{c m}\right), e_{m r}\left(=-e_{r m}\right)$ and $e_{m s}\left(=-e_{s m}\right)$.

Finding appropriate closure relations to the exchange terms of the mass balance equations, as a flux-based approach, is at the core of the REW approach. Using physical principles, by means of the momentum balance, energy balance and entropy concept, is one of the approaches to close the equation systems. However, while reviewing other work on the REW approach we have observed that momentum balance analysis does not always or necessarily lead to (proper) functional expressions. Without correct field experiments at the scale of interest (in this case, the REW scale), it is hard to prove that the forces acting across the REW-scale boundaries, which are not easy to be defined and rather conceptual, are the real physics governing the hydrological processes at such scale. Therefore, in parameterising the balance equations and closure equations, case-by-case (or ad hoc) assumptions are unavoidable. Moreover, as many authors (e.g. Lee at al., 2005; Zehe et al., 2005; Zhang and Savenije, 2005; Beven, 2006) have discussed, there are a number of options to the closure problem, for instance, regression analysis based on detailed numerical experiments and/or field observations, and physical reasoning based on intuitive grounds. These methods for closure are conceptual but with a physical background. One should realise that a large advantage of the REW approach is that as long as the closure relations used are transparent and well motivated, it offers a consistent framework for hypothesis testing. Keeping this in mind, we followed a conceptual approach to formulate the new domain and the associated functional relations to close the new mass balance equations.

\section{Infiltration flux to the macropore domain}

During a rainfall event, the effective rainfall infiltrates into both the soil matrix (the unsaturated domain) and the macropore domain. It is hypothesised that the flow to the macropore domain is initiated only after the infiltration capacity of the unsaturated domain is exceeded. This means, similar to the MCARO approach (Jarvis, 2004), that the effective rainfall is partitioned into the fluxes $e_{c u}$ and $e_{c m}$. The partitioning is determined by the infiltration capacity of the unsaturated domain. This assumption, which excludes the infiltrationexcess overland flow process, is motivated by the fact that in the study area infiltration-excess overland flow hardly occurs. However, this assumption should be re-examined when the model is applied to any Hortonian-flow dominated 
watershed, even if preferential flow processes are important (e.g. Zehe and Blöschl, 2004).

In Zhang and Savenije (2005), the infiltration flux to the unsaturated domain is expressed as:

$e_{c u}=\min \left[\left(i-i_{d c}\right), f\right] \rho \omega_{u} A$

where $f$ is the infiltration capacity of the soil matrix, represented by:

$f=\frac{K_{s u}}{\Lambda_{u}}\left(\frac{1}{2} y_{u}+h_{c}\right)$

where $K_{s u}\left[\mathrm{LT}^{-1}\right]$ is the saturated hydraulic conductivity of the unsaturated domain, $\Lambda_{u}[\mathrm{~L}]$ is a representation of the length scale of the wetting front, and $h_{c}[\mathrm{~L}]$ is the suction head of the unsaturated domain that is evaluated using the Brooks-Corey method (Brooks and Corey, 1964). As a result, the infiltration flux to the macropore domain can be written as:

$e_{m c}=\left\{i-i_{d c}-\min \left[\left(i-i_{d c}\right), f\right]\right\} \rho \omega_{u} A$

In Eqs. (7), (8) and (9), $\left(i-i_{d c}\right)$ represents the effective rainfall in which $i$ and $i_{d c}$ are the rainfall intensity and the rainfall interception, respectively.

\section{Fluxes out of the macropore domain}

It is commonly assumed that the capillary effect is insignificant for water flow in the macropore domain. Consequently, the downward unit area flux (i.e. the velocity of the flow) of this domain can be approximated by

$v_{m}=-K_{m}$

where $K_{m}\left[\mathrm{LT}^{-1}\right]$ is the hydraulic conductivity of the macropore domain. Taking into account the anisotropy of the flow conductance in the macropore media, $v_{m}\left[\mathrm{LT}^{-1}\right]$ can be decomposed into a lateral component, which is a function of the terrain slope and contributes to the stream channel along the terrain slope, and a vertical component, contributing to the saturated aquifer as recharge. We defined the following expressions to determine these two fluxes:

$v_{m r}=-K_{m l} \sin \gamma_{o}$

$v_{m s}=-K_{m v}$

where $v_{m r}\left[\mathrm{LT}^{-1}\right]$ and $v_{m s}\left[\mathrm{LT}^{-1}\right]$ are the velocity for the flow towards the river channel and towards the saturated domain respectively; $K_{m l}\left[\mathrm{LT}^{-1}\right]$ and $K_{m v}\left[\mathrm{LT}^{-1}\right]$ are the hydraulic conductivity for the lateral flow and the vertical flow respectively; $\gamma_{o}[-]$ is the average slope of the hillslope. Negative signs represent water flowing out of the domain in question. As a result, the lateral flux to the river $e_{m r}\left[\mathrm{LT}^{-1}\right]$ is determined by:

$e_{m r}=\rho v_{m r} A_{m r}$ where $A_{m r}\left[\mathrm{~L}^{2}\right]$ is the flow area perpendicular to the flow direction. $A_{m r}$ can be approximated by

$A_{m r}=w_{m} D_{m}$

where $w_{m}[\mathrm{~L}]$ and $D_{m}[\mathrm{~L}]$ are the flow width and depth respectively. As we can conceptualise that the lateral flow is conducted through the saturated macropore media, the flow depth is thus evaluated by

$D_{m}=y_{m} s_{m}$

where, same as in Eq. (4), $y_{m}$ and $s_{m}$ are the average thickness and the saturation degree of the macropore domain, $y_{m}$ equals to $y_{u}$. The flow width $w_{m}[\mathrm{~L}]$ is assumed to equal the length of the receiving river channel, $l_{r}[\mathrm{~L}]$. Thus, it results in

$A_{m r}=y_{u} s_{m} l_{r}$

Substituting Eqs. (11), (16) into Eq. (13), and further assuming that the river channel is fed by hillslopes symmetrically from its two sides, it yields

$e_{m r}=-2 \rho K_{m l} y_{u} s_{m} l_{r} \sin \gamma_{o}$

The flux to the saturated domain $e_{m s}\left[\mathrm{MT}^{-1}\right]$ can be described by

$e_{m s}=\rho v_{m v} A_{m s}$

where $A_{m s}\left[\mathrm{~L}^{2}\right]$ is the area of the flow perpendicular to $v_{m s}$, which can be evaluated by

$A_{m s}=A \omega_{m} s_{m}$

where $A \omega_{m}$ represents the part of the area of the REW occupied by the macropore domain. The involvement of $s_{m}$ in Eq. (19) is due to the assumption that the flow is conducted through the water phase, same as for Eq. (15). Substituting Eqs. (12), (19) into Eq. (18) yields

$e_{m s}=-\rho K_{m v} A \omega_{m} s_{m}$

As a result, a complete description for the macropore flow has been obtained in terms of the continuity equation and the closure relations:

$\left\{\begin{array}{l}\frac{\mathrm{d}\left(\rho \varepsilon_{m} s_{m} y_{u} \omega_{m} A\right)}{\mathrm{d} t}=e_{m c}+e_{m r}+e_{m s} \\ e_{m c}=\left\{\left(i-i_{d c}\right)-\min \left[\left(i-i_{d c}\right), f\right]\right\} \rho \omega u A \\ e_{m r}=-2 \rho K_{m l} y_{u} s_{m} l_{r} \sin \gamma_{o} \\ e_{m s}=-\rho K_{m v} A \omega_{m} s_{m}\end{array}\right.$

This set of equations governs macropore flow at catchment scale and has been implemented in REWASH code. This set of equations represents an exceptional case of the conventional kinematic wave approach (e.g. Beven and Germann, 1981) for small scale preferential flow, in which storage and flow is nonlinearly related. 


\section{Numerical simulation}

\subsection{Site description and data used}

The revised REWASH was applied to the Hesperange catchment and a rainfall runoff model was constructed. The Hesperange catchment is a sub-basin of the southern Alzette river basin that is located upstream of Luxembourg City, covering an area of $292 \mathrm{~km}^{2}$ (Fig. 2). Lithology of the Hesperange catchment is mainly characterized by marls and sandstones on the left bank tributaries, and limestones on the right bank tributaries of the Alzette River.

The runoff behaviour of marly areas is characterized by a fast response to rainfall, with a rapid streamflow increase during rainfall events, and relatively low discharges during dry weather periods. This behaviour is explained considering that the marls rock mass is of a low hydraulic conductivity, hampering deep percolation of water. The storage capacity of marls formation is therefore relatively low. Marls areas are overtopped by a shallow layer of loamy-clayey soil, which saturates quickly during rainfall events. Streamflow is sustained, for the large part, by subsurface flow, which likely occurs at the contact between the soil and the underlying bedrock layer.

The limestone areas, in contrast, can be considered as a large reservoir capable of storing and releasing large quantities of water. Limestone formations are strongly fractured and are located on top of a marls confining stratum. Except where the water table has reached the soil surface, all water that reaches the ground infiltrates into the soil. Stream flow is mostly sustained by groundwater, which occurs either as springs at the contact between the sandstone and the marls formation, or by channel incision of the water table.

The study site is instrumented by several rain gauges, stream gauges and piezometric gauges. For the present study, we used daily data of rainfall, discharge, potential evaporation (1997-2000). The rainfall series for the Hesperange catchment were calculated using the Thiessen polygons interpolation method. Daily potential evaporation values are estimated with the Hamon equation (Hamon, 1961), using daily temperature values measured at Luxembourg airport. Discharge gauging stations at the Livange and the Hesperange are located along the main course of the Alzette River while stations at Mierbech and the Dudelingerbach reside in two of the tributaries. Piezometric levels measured at Fentange from 1997 to 2000, at Dumontschaff and Bettembourg in the year 2000, are available (Fig. 3). A digital elevation model (DEM) with $50 \mathrm{~m} \times 50 \mathrm{~m}$ resolution is used for sub-catchment delineation and spatial analysis.

\subsection{Model simulations}

The Hesperange catchment was delineated using TARDEM software (Tarboton, 1997). Using the third order Strahler threshold, 15 REWs were identified (Fig. 3) and their re-

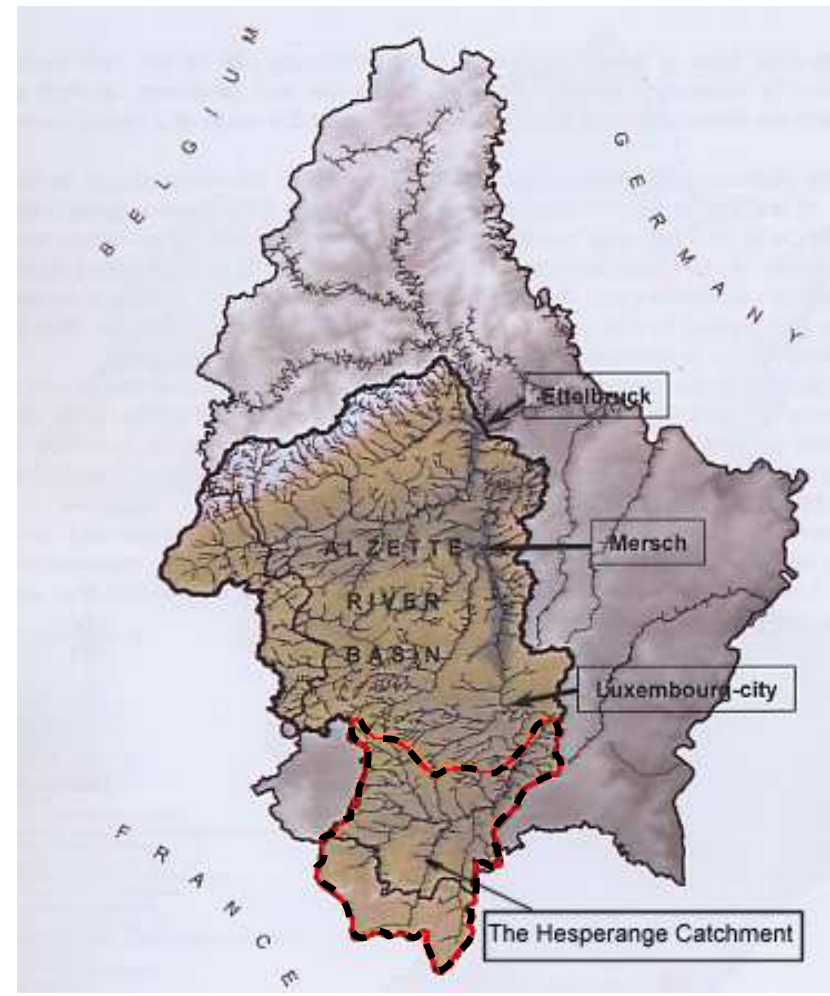

Fig. 2. Location of the Hesperange catchment.

spective geometric information were extracted. In the whole simulation processes, each parameter was kept homogeneous over the entire catchment due to lacking information on the distribution of parameters. Parameters were initialised empirically while literature reported values have been taken into account.

The simulations have been carried out through model calibration and verification steps. A comparison based on simulations with and without the macropore domain has been performed. Rainfall and potential evaporation data were used as the model driving force input while discharge data measured at the catchment outlet were used to check against the simulated hydrograph. In the calibration step, both manual and automatic calibration methods have been applied. During manual calibration, the reasonable ranges of parameters' value were determined. Subsequently, the GLOBE software, using a global search algorithm developed by Solomatine $(1995,1999)$, was applied to search the optimal parameter set. Nash-Sutcliffe efficiency (Nash and Sutcliffe, 1970 ), $R_{N S}^{2}$, has been used for the objective function for automatic calibration. Most attention was given to parameters for the macropore domain: $K_{m l}$ (lateral hydraulic conductivity), $K_{m v}$ (vertical hydraulic conductivity), $\varepsilon_{m}$ (porosity); for the unsaturated domain: $K_{s u}$ (saturated hydraulic conductivity), $\varepsilon_{u}$ (porosity); for the saturated domain, $\varepsilon_{s}$ (porosity); and for the river domain: $K_{s r}$ (hydraulic conductivity of the river bed layer). The rainfall interception threshold $i_{d c}$ was 


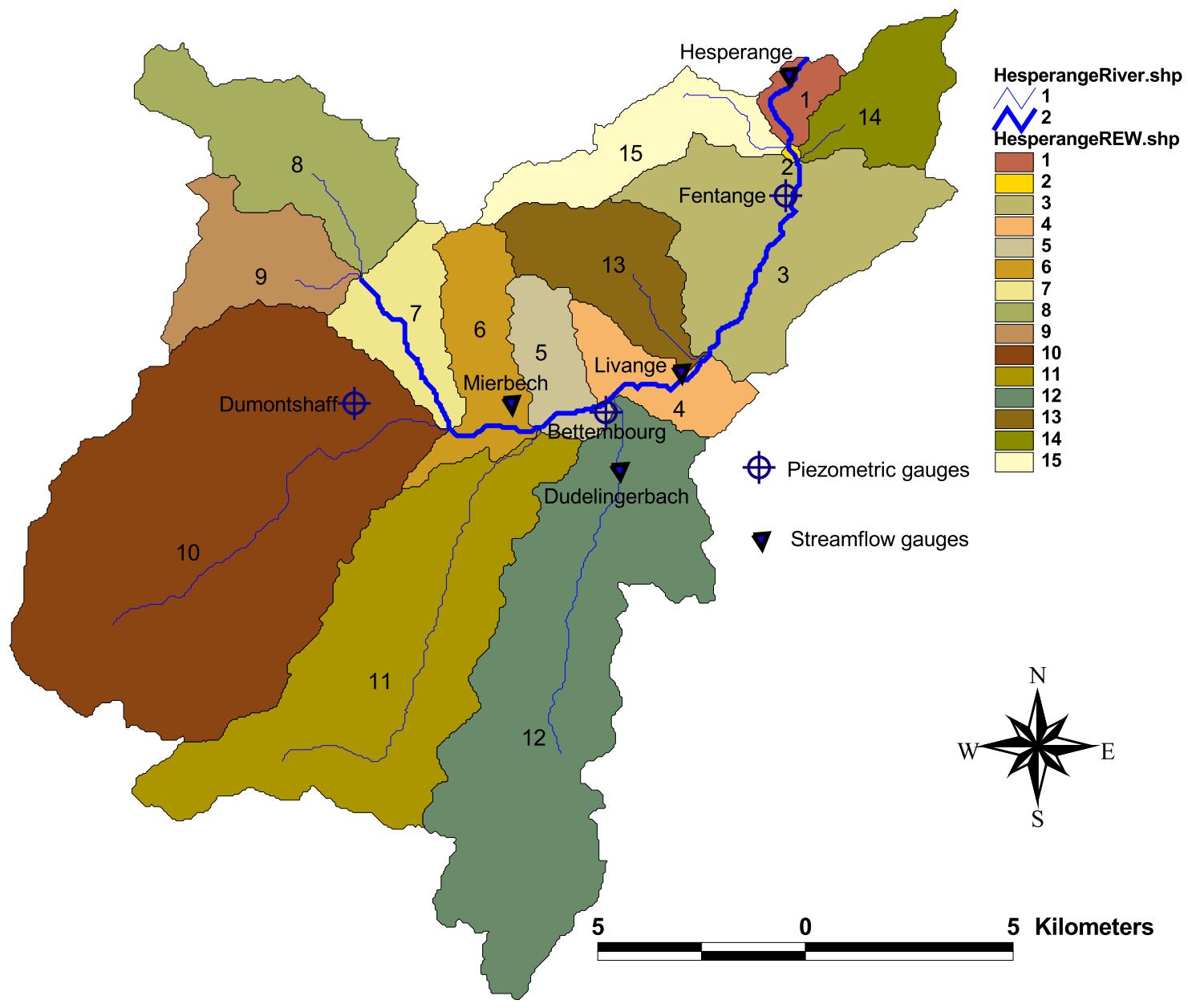

Fig. 3. Delineation of the REWs for the Hesperange catchment and distribution of the gauging stations.

also subject to calibration. To verify the model, not only the simulated discharge at the catchment outlet, but also the simulated discharges and groundwater tables at various locations within the subwatersheds were compared with the respective observations.

\section{Results}

\subsection{Model calibration}

The model has been calibrated on 4 years (1997-2000) of data . For the purpose of validation, the model has first been calibrated on the data from 1997 to 1999 and subsequently verified by the split-sample test using the data of the year 2000 (see Table 2). Since there is a large parameter space, the uncertainty bound was constrained by prescribing reasonable ranges of the physical parameters after a sequence of trialand-error model runs (Table 1). Over 800 calibration runs resulted in less than 10 parameter sets with a Nash-Sutcliffe efficiency that is slightly larger than 0.70 . The optimum was obtained with $R_{N S}^{2}=0.70$ and a discharge volume bias (see Zhang and Savenije, 2005) $\delta_{B}=0.98 \%$. The simulated discharges are presented in Fig. 4. The optimised parameter values and model performance index values are reported in Tables 1 and 2 . It can be seen that the model successfully simulated the general rainfall runoff relation of the catchment. In general, peaks and recession limbs are more accurately simulated than low flows. Figure 5 plots the simulated and the observed hydrographs at a logarithmic scale. It shows clearly that base flows in drier periods are underestimated. It also can be seen that in drier periods some small peaks are overshot, while in the period (Day 680 to Day 820) when there are consecutive rainfall events, peaks are underestimated. This indicates that the model responds more strongly to the rainfall than the real system does.

Although there are no observations available on subsurface storm flow to test the simulated subsurface storm flow, we compared the simulated hydrograph with observations for two models: one with and one without the macropore flow domain. It is clearly demonstrated that the model with the macropore flow domain performs better $\left(R_{N S}^{2}=0.70\right)$ than the 
(a)

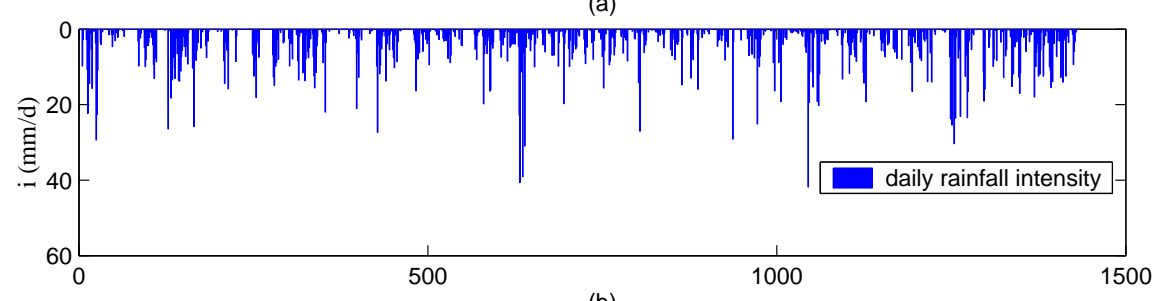

(b)

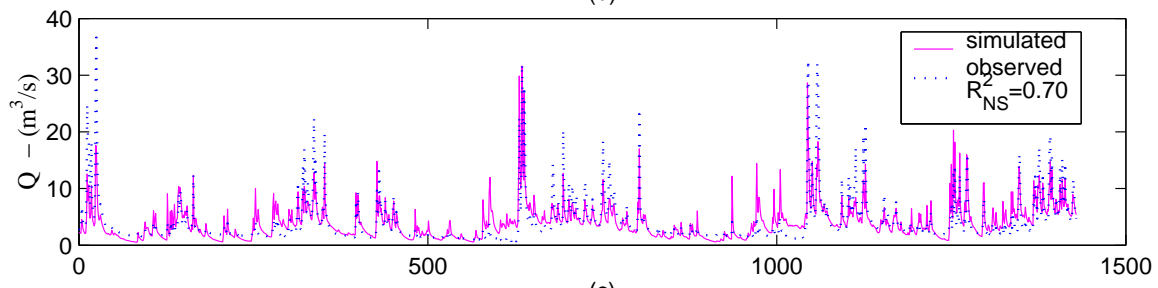

(c)

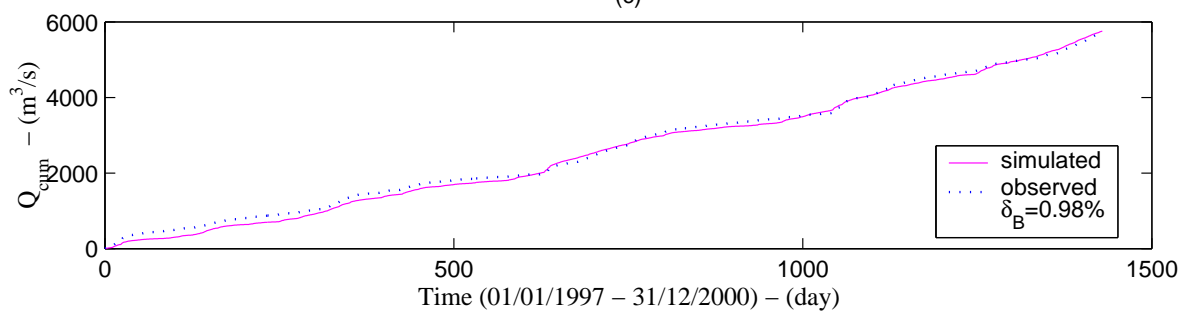

Fig. 4. (a) Rainfall intensity of the Hesperange catchment; (b) Comparison of the observed and the simulated hydrographs at the outlet of the Hesperange catchment (1 January 1997-31 December 2000); (c) Comparison of the observed and the simulated cumulative discharges at the outlet of the Hesperange catchment.

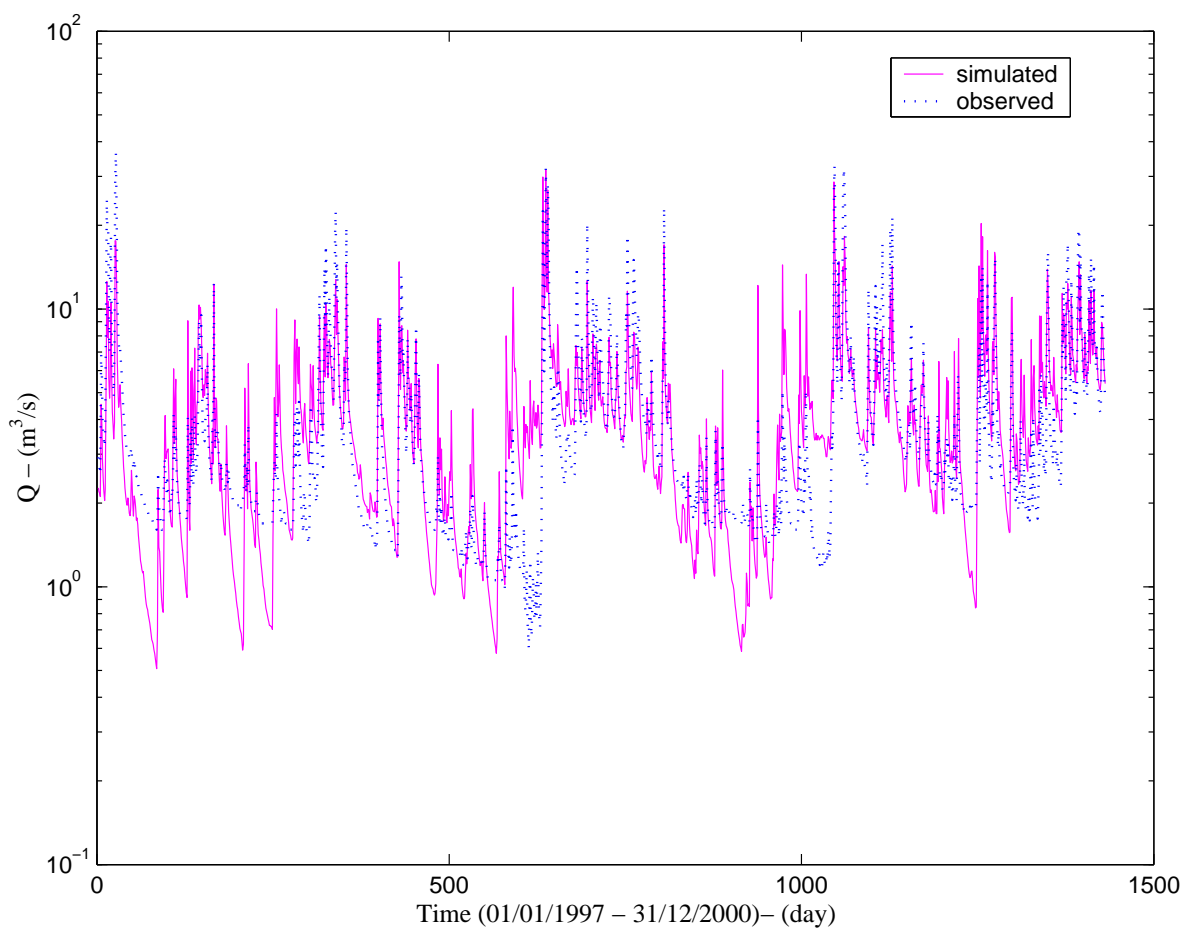

Fig. 5. The observed and the simulated discharge at the outlet of the Hesperange catchment for the calibration period (1 January 1997-31 December 2000) plotted on logarithm scale. 


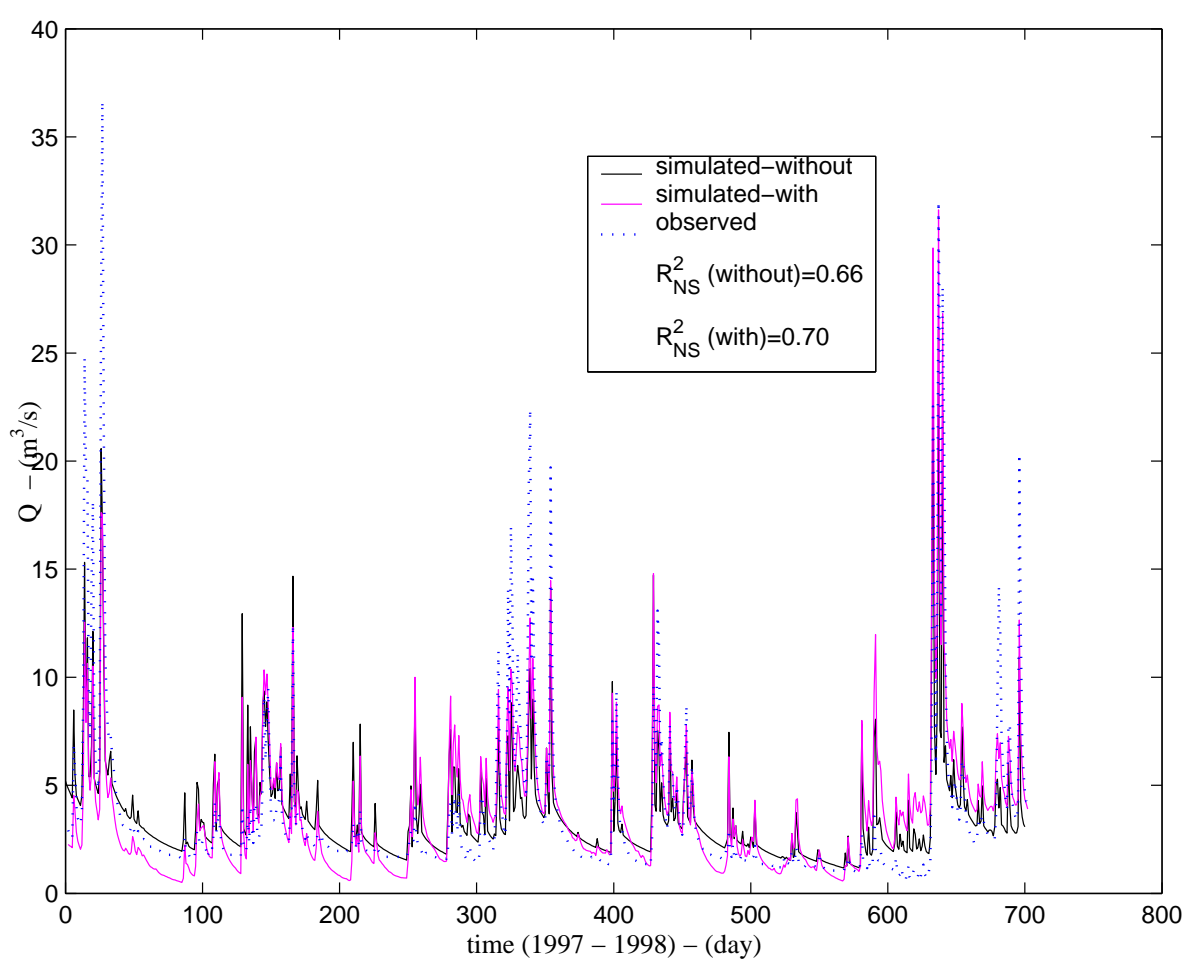

Fig. 6. Comparison of the simulated outlet hydrograph without the macropore flow domain (black solid line), with the macropore domain (pink solid line) and the observed outlet hydrograph (blue dotted line).

Table 1. Parameters, their value ranges for calibration and the final optimised values.

\begin{tabular}{lll}
\hline Parameter & Range & Value \\
\hline$K_{m l}\left[\mathrm{~ms}^{-1}\right]$ & $1.0 \mathrm{e}-6-1.0 \mathrm{e}-1$ & $3.35 \mathrm{e}-5$ \\
$K_{m v}\left[\mathrm{~ms}^{-1}\right]$ & $1.0 \mathrm{e}-12-1.0 \mathrm{e}-4$ & $3.58 \mathrm{e}-9$ \\
$K_{s u}\left[\mathrm{~ms}^{-1}\right]$ & $1.0 \mathrm{e}-12-1.0 \mathrm{e}-6$ & $1.83 \mathrm{e}-10$ \\
$K_{s r}\left[\mathrm{~ms}^{-1}\right]$ & $1.0 \mathrm{e}-6-1.0 \mathrm{e}-1$ & $1.90 \mathrm{e}-4$ \\
$\varepsilon_{m}[-]$ & $0.05-0.5$ & 0.15 \\
$\varepsilon_{u}[-]$ & $0.05-0.5$ & 0.33 \\
$\varepsilon_{s}[-]$ & $0.01-0.2$ & 0.05 \\
$i_{d c}\left[\mathrm{md}^{-1}\right]$ & $5.0 \mathrm{e}-4-1.0 \mathrm{e}-2$ & $1.05 \mathrm{e}-3$ \\
$n\left[\mathrm{sm}^{-1 / 3}\right]$ & $1.0 \mathrm{e}-3-2.0 \mathrm{e}-1$ & 0.08 \\
$\alpha_{s f}[-]$ & $0.05-0.65$ & 0.55 \\
\hline
\end{tabular}

model without the macropore domain $\left(R_{N S}^{2}=0.66\right)$. Figure 6 presents the comparison of the two modelling results. We also present the different components of the stream flow to evaluate the significance of the subsurface storm flow contribution to the stream flow. Figure 7 illustrates the composition of the various flux components for two of the subcatchments, REW 8 and REW 9. We selected these two REWs because they are headwater watersheds to which there are no lateral or side channel flows disturbing the analysis of stream flow composition resulting from routing effects. To
Table 2. Model performance for different simulation periods.

\begin{tabular}{lll}
\hline & $R_{N S}^{2}$ & $\delta_{B}$ \\
\hline Calibration (1997-2000) & 0.70 & $0.98 \%$ \\
Calibration (1997-1999) & $0.71 *$ & $6.3 \%$ \\
Validation (2000) & 0.65 & $2.1 \%$ \\
\hline
\end{tabular}

$* R_{N S}^{2}$ of individual year are $0.65,0.72$ and 0.71 for 1997,1998 and 1999 , respectively.

avoid a congested graphical view, only a few events and the corresponding simulations are presented. The stream flow is the result of direct rainfall on the channel flow surface $\left(e_{\text {top }}\right)$, subsurface storm flow $\left(e_{m r}\right)$, overland flow $\left(e_{o r}\right)$, and base flow $\left(e_{s r}\right) . e_{t o p}$ is of minor effect on the stream flow. Obviously, $e_{o r}$ determines the peaks. Subsurface flow, $e_{m r}$, however, makes a significant contribution to the storm runoff. It clearly shows that $e_{m r}$ dominates the flood events when rainfall intensity becomes smaller. The slopes of the recession limbs are reduced due to the subsurface storm flow.

Figure 8 represents the simulated saturation overland flow area fraction $\left(\omega_{o}\right)$ for four headwater sub-watersheds. Analysing the results of each of the $15 \mathrm{REWs}$, we found out that $\omega_{o}$ varies between 0.23 and 0.47 . However, $\omega_{o}$ fluctuates within a much smaller range that is from $3 \%$ to $8 \%$. 
(a) Catchment Rainfall

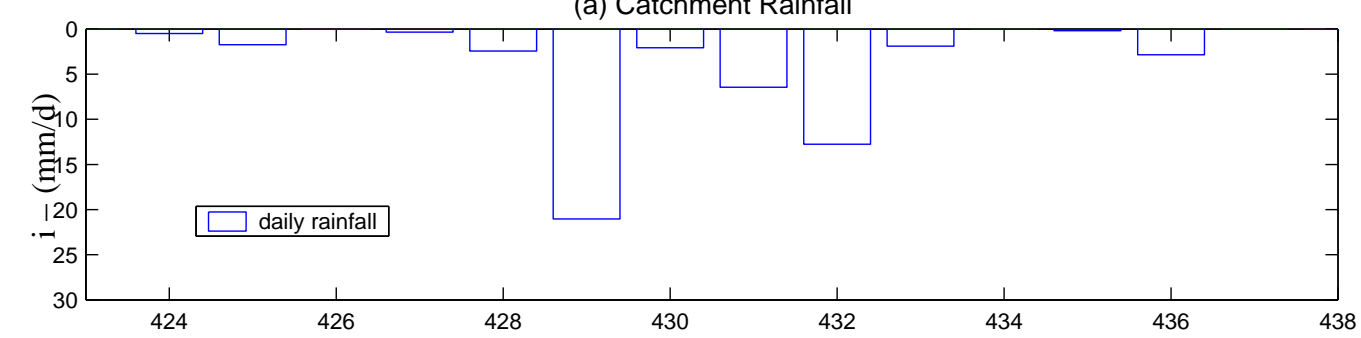

(b) REW 8

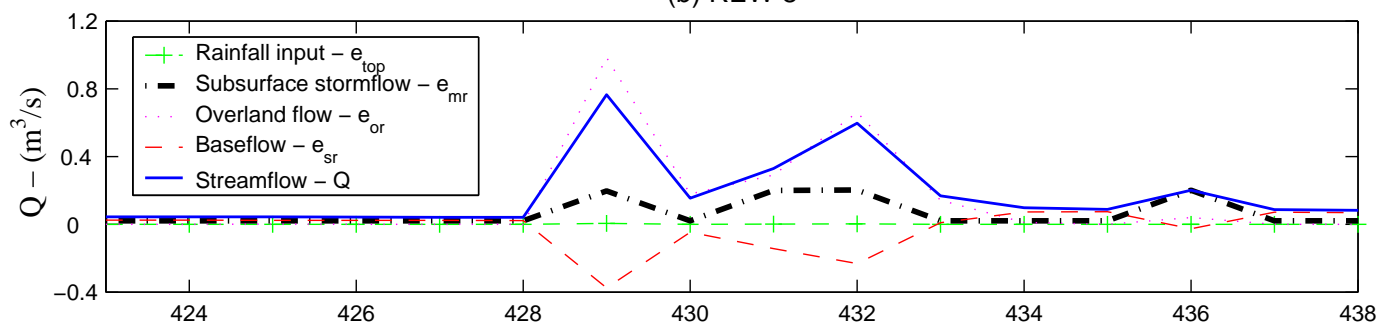

(c) REW 9

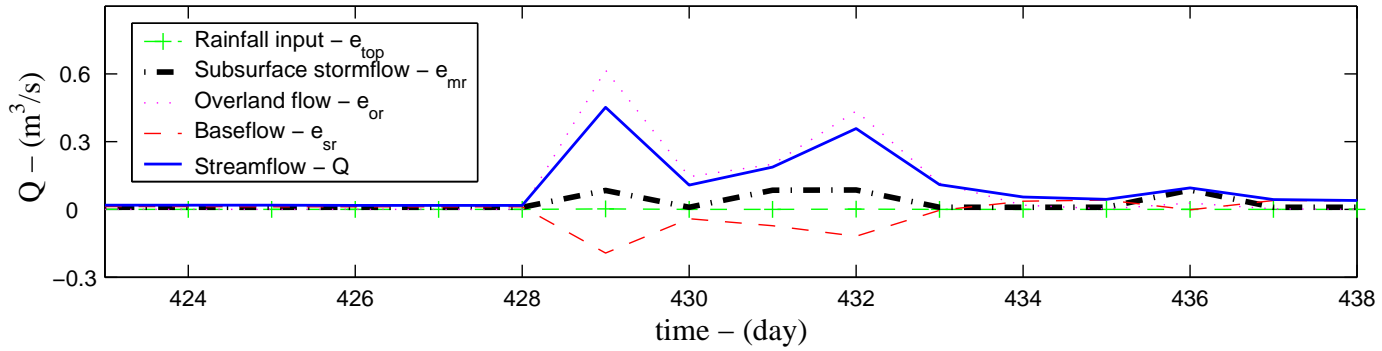

Fig. 7. (a) Rainfall events (1 March 1997-15 March 1997); (b) Flux components contributing to stream flow in the river channel of the REW 8; (c) Flux components contributing to stream flow in the river channel of the REW 9. Pink dotted line: overland flow - $e_{o r}$; Blue solid line: stream flow $-Q$; Black dash-dot line: subsurface stormflow $-e_{m r}$; Green dashed line with plus marker: rainfall input $-e_{\text {top}}$; Red dashed line: baseflow $-e_{s r}$.

\subsection{Multi-criteria model evaluation}

\subsubsection{Model validation}

Model validation was conducted firstly through the splitsample test described above, but further evaluated with the multi-site and multi-variable approach (Refsgaard, 1997; Madsen, 2003), using discharge data measured at interior gauging stations (the Livange, the Mierbech and the Dudelingerbach, see Fig. 3) and groundwater table variations observed at three piezometers.

Discharge observed between 1 January 1997 and 31 December 1999 at the Livange station, about $10 \mathrm{~km}$ upstream of the outlet of the catchment on the main river course, was compared with the simulated discharge for the REW 4 where the gauging station resides. The total Nash-Sutcliffe efficiency is slightly over 0.65 , while it is around 0.57 for 1997 , 0.73 for 1998 and 0.64 for 1999 respectively. From Fig. 9, we can see that peaks are generally underestimated. However, we found out that some peaks measured at this location are higher than those measured at the catchment outlet, in- dicating that potential errors contained in the measurement should be cautiously taken into account in the evaluation of the model.

The Mierbech gauge, located in REW 6, records the stream flow for a small tributary to the main river course. However, the catchment delineation of this study did not generate this river branch. Therefore, we computed the hillslope discharge of REW 6 by summing the contributing fluxes, $e_{o r}$, $e_{m r}$ and $e_{s r}$. The model was run for the complete 4 years using the calibrated parameters and then compared with the observed hydrograph (Fig. 10). One can still recognise that the watershed response is well represented although $R_{N S}^{2}$ is as low as 0.33 . Figure 11 presents the simulated hydrograph for the river branch in REW 12 and the hydrograph observed at the Dudelingerbach station. The plot shows that the general pattern of the stream flow is recognised by the model, however, the model efficiency with respect to this REW is low. 
(a)

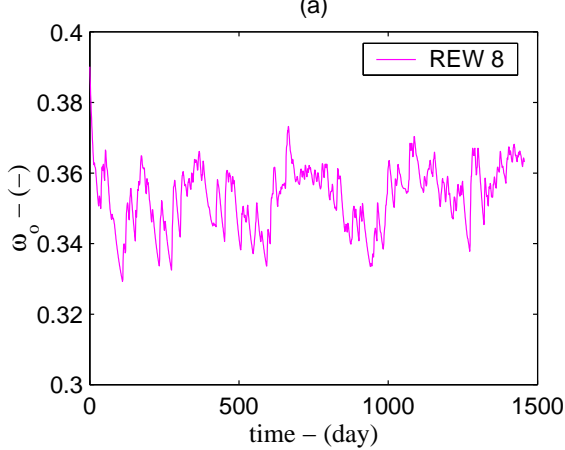

(c)

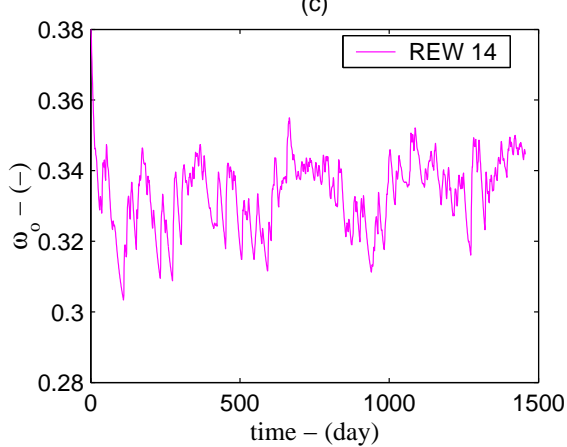

(b)

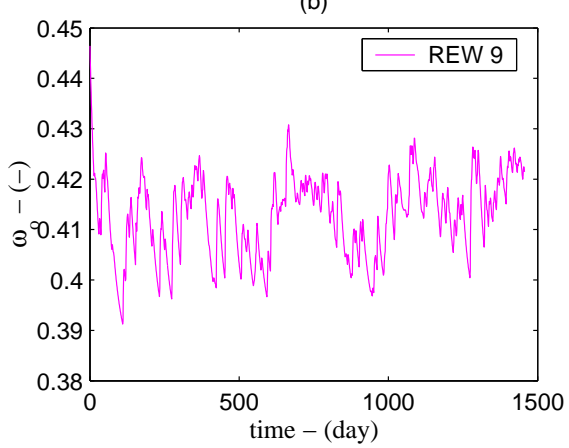

(d)

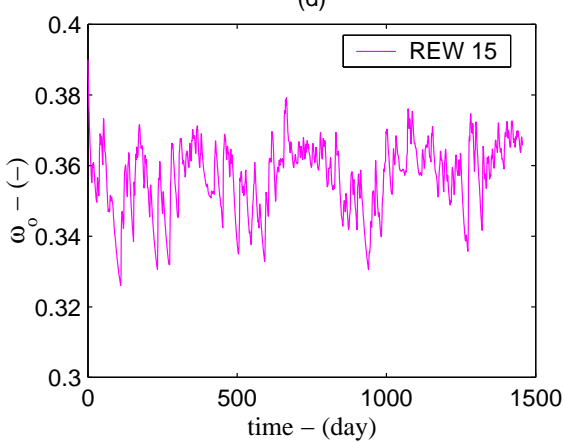

Fig. 8. Simulated variable source area fraction for (a) REW 8, (b) REW 9, (c) REW 14 and (d) REW 15.

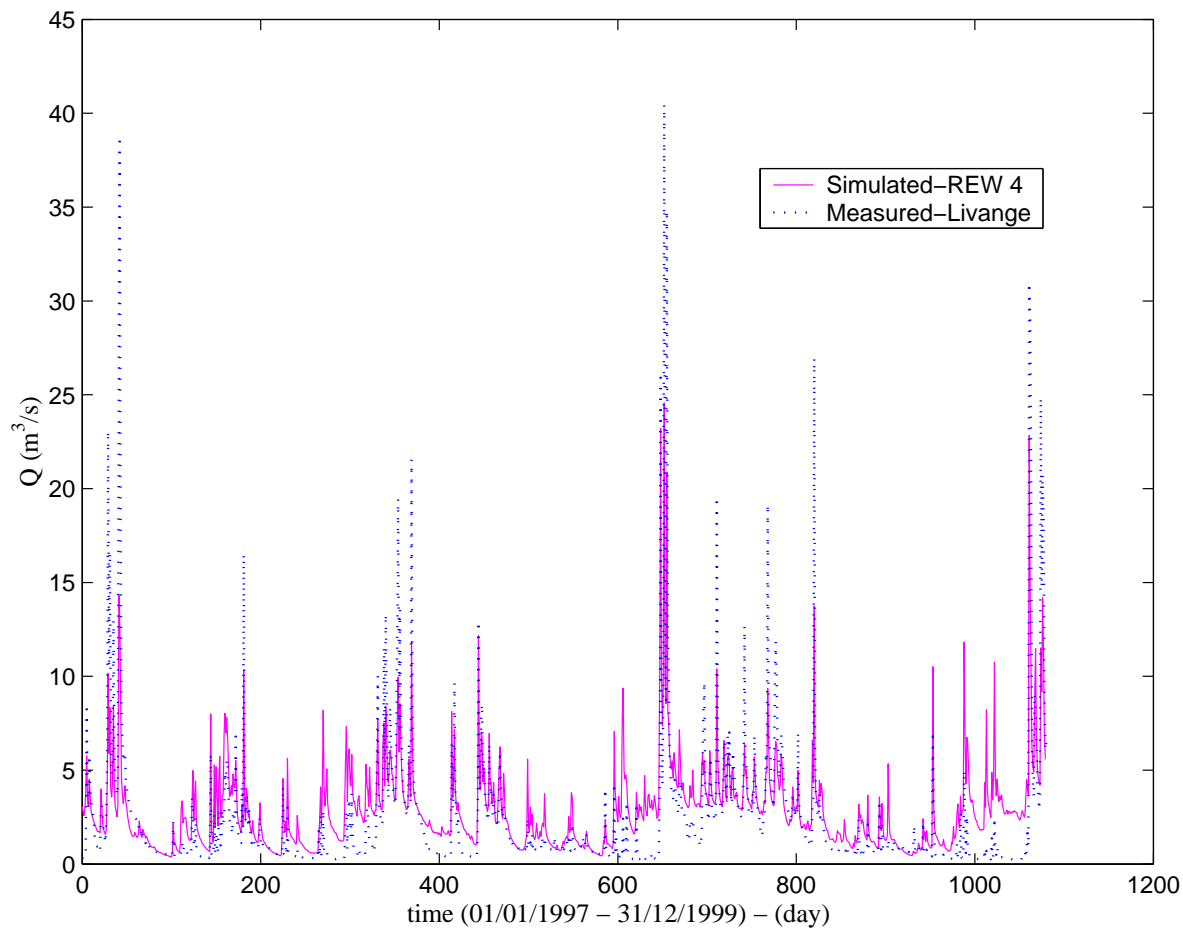

Fig. 9. Comparison of the observed and the simulated stream flow at the Livange gauging station for the period of 1 January $1997-31$ December 1999. The station is located in the sub-catchment REW 4. 


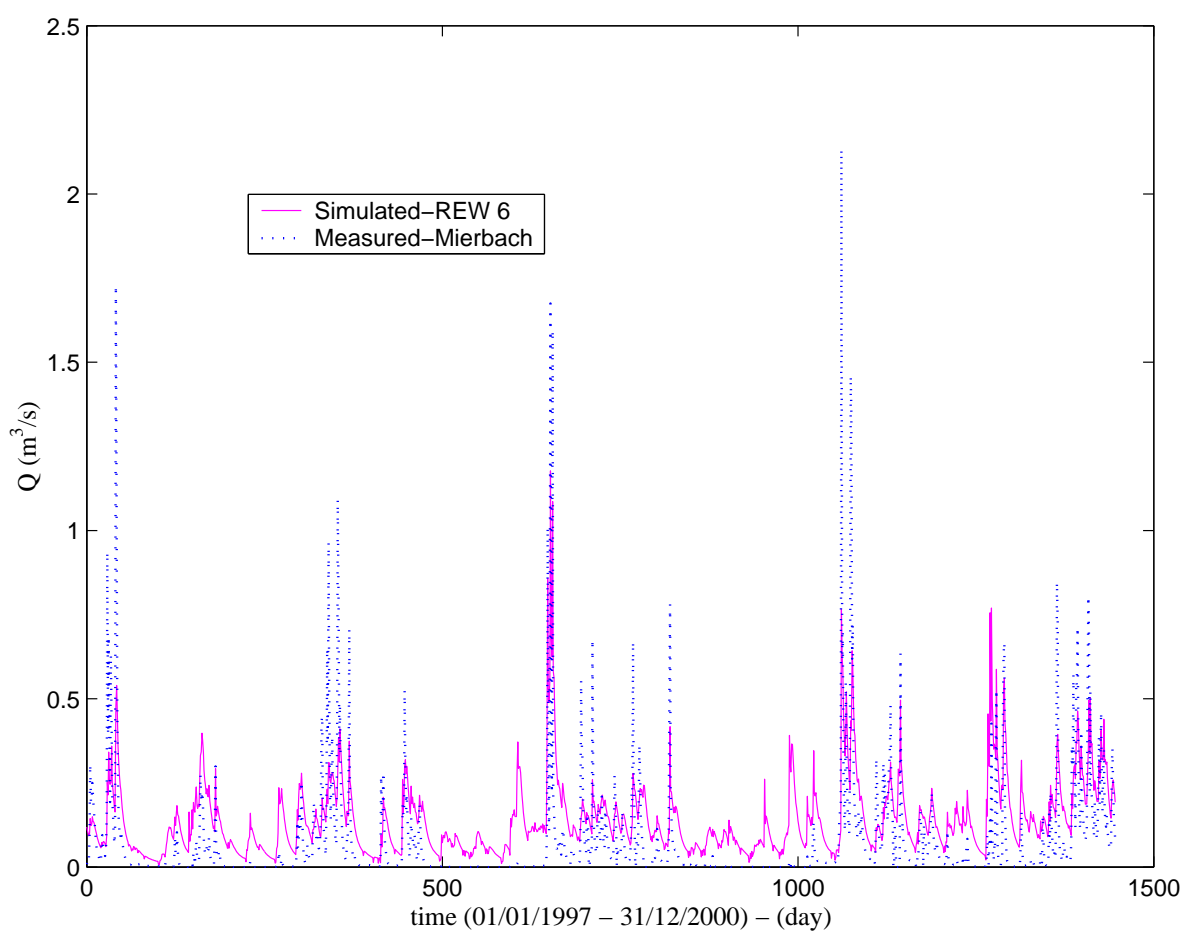

Fig. 10. Comparison of the observed and the simulated stream flow at the Mierbech gauging station (1 January 1997-31 December 2000). The station is located in the sub-catchment REW 6.

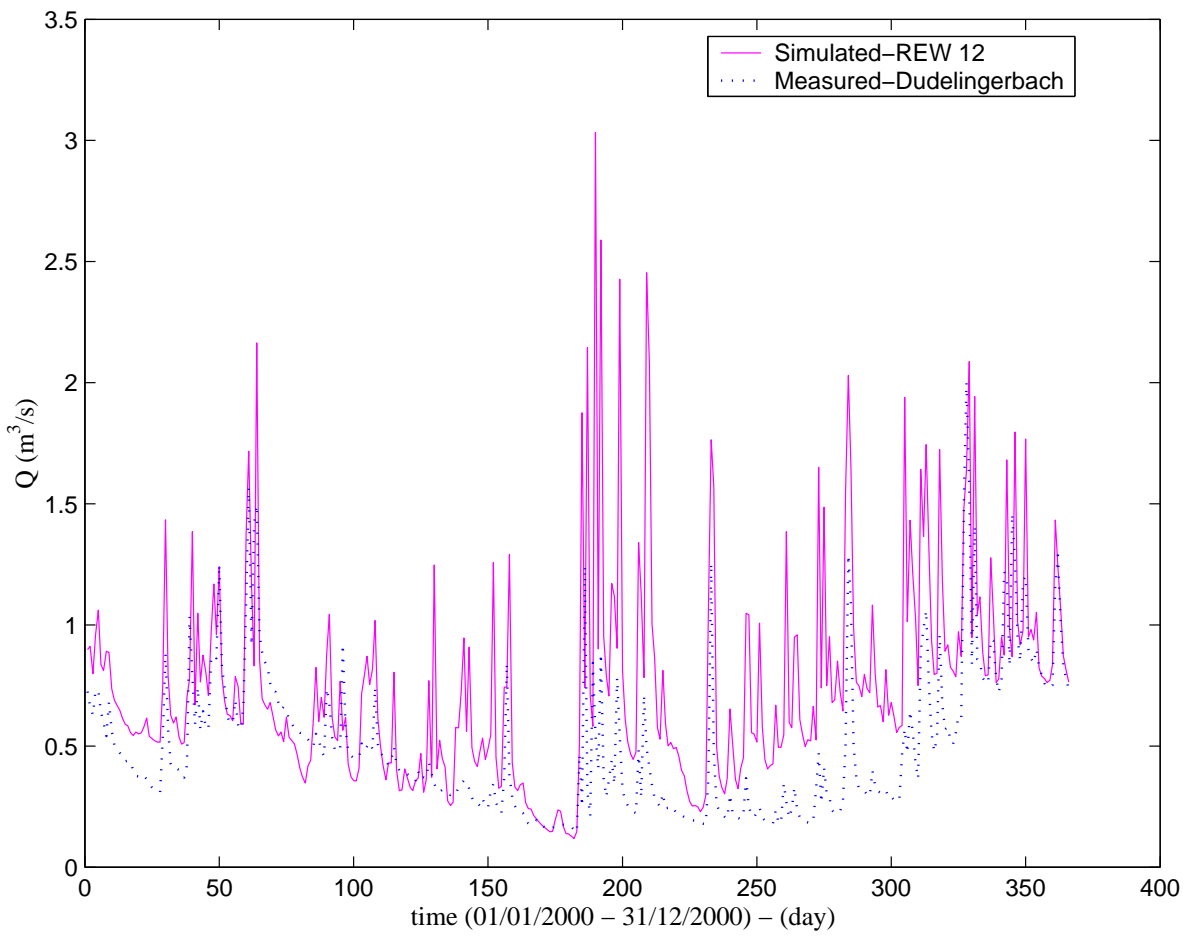

Fig. 11. Comparison of the observed and the simulated stream flow at the Dudelingerbach gauging station (1 January 2000-31 December 2000). The station is located in the sub-catchment REW 12. 

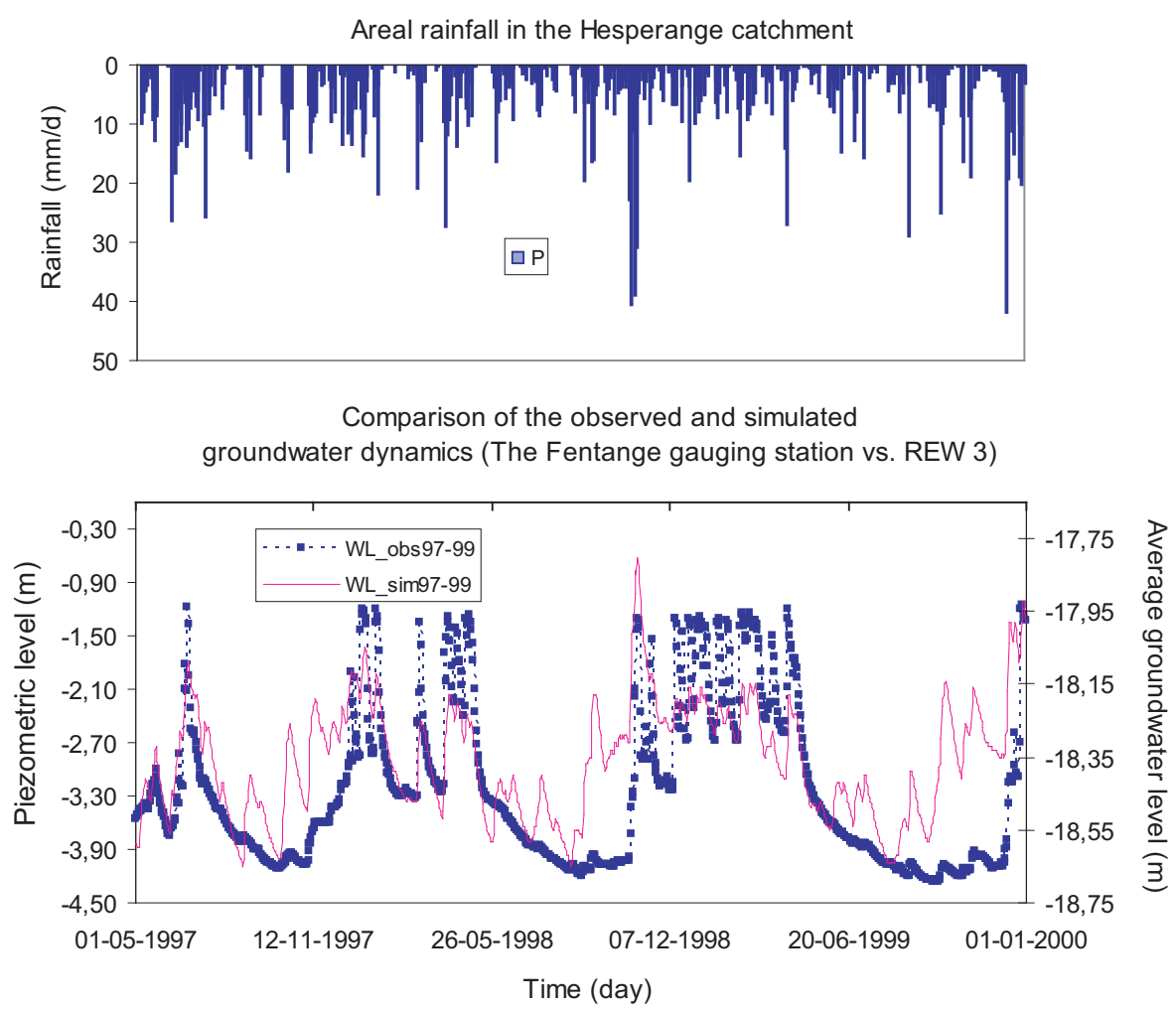

Fig. 12. Comparison of the observed and the simulated groundwater dynamics of the sub-catchment REW 3 (1 May 1997-31 December 1999).

\subsubsection{Groundwater table dynamics}

Being a physically based model, predicting the integral catchment response is not the only objective. Therefore, the internal process representation (e.g., soil moisture content and groundwater dynamics) is desirably to be evaluated. Especially, the subsurface system of a well vegetated catchment in humid region plays a vital role in hydrological cycle and water balance regime. On that account, we used the available piezometric measurements at three locations in the study area to check the model functioning in terms of representing watershed scale patterns of the groundwater dynamics. Since the piezometric levels are point scale measurements while the simulated groundwater levels are REW (i.e. watershed) scale quantities, one can expect scale discrepancies between the two. Figure 12 presents the observed piezometric level at the Fentange and the simulated average groundwater level for REW 4, from 1 May 1997 to 31 December 1999 at daily time step. The result shows an impressively good match between the simulated and observed time series with respect to the general trend and the seasonal variation. The fluctuation of the piezometric level at the Fentange is within a range of $3.12 \mathrm{~m}$ while the fluctuation of the average groundwater level of REW 3 is within $0.85 \mathrm{~m}$. On the other hand, we also observed that the model is more responsive to rainfall events during drier periods than the measured piezometric levels. This behaviour is also exhibited in hydrograph simulations described earlier.

The average groundwater levels simulated for REW 5 and REW 10 in the model verification year 2000 were compared with the piezometric levels measured at the Bettembourg and the Dumontshaff (Figs. 13, 14), respectively. The model simulated the average groundwater level of REW 5 varying within a range of $0.34 \mathrm{~m}$ while the measured fluctuation at the Bettembourg is $0.74 \mathrm{~m}$. The simulated dynamics accurately concurs with the observed. The results of REW 10 also show a good agreement between the simulated and the observed series in variation pattern. The piezometer level at the Dumontshaff is within a range of $0.98 \mathrm{~m}$, the simulated one is within $0.32 \mathrm{~m}$.

\section{Discussion}

The model represents the characteristics of the fast runoff response to rainfall in the catchment. On a daily time step, there is almost no lag between rainfall and runoff at the outlet. Rising limbs of the hydrograph are abrupt and steep, which are well simulated. It has been reported in the previous section that discharges are underestimated in a period when 

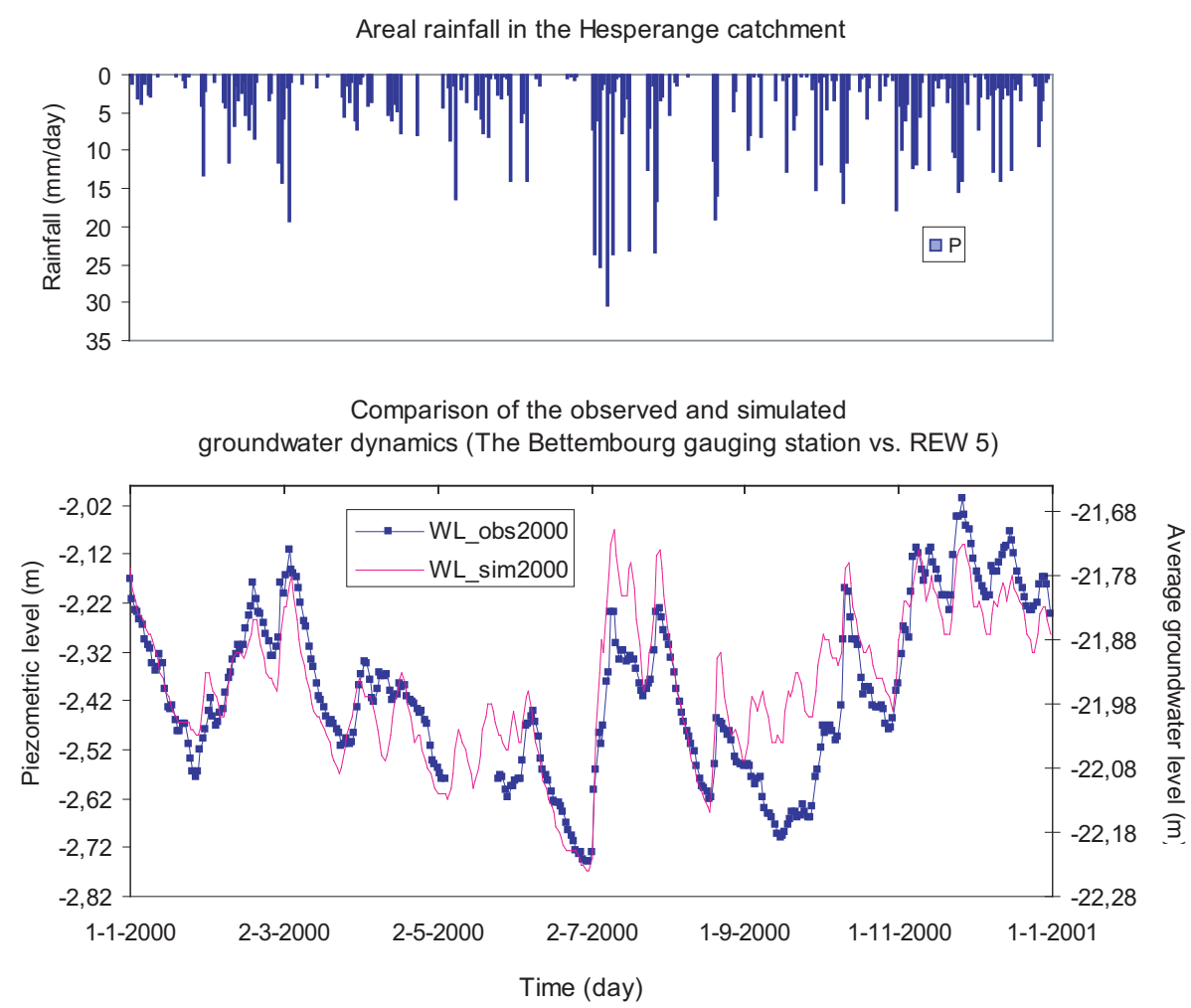

Fig. 13. Comparison of the observed and the simulated groundwater dynamics of the sub-catchment REW 5 (1 January 2000-31 December 2000).

rainfall events follow wet antecedent conditions, whereas discharges are overestimated for events after a long dry spell. There are two possibilities that can cause this deficiency. One is that the model is possibly weak in memorising the history, i.e., deficient in soil moisture accounting; the other is that the rainfall data may contain errors since they have been computed as daily areal rainfall over the catchment. In other words, the threshold behaviour is disturbed. To further investigate this issue, using local rainfall records in a distributed manner and/or comparing with other model results, may be a next step towards a better understanding.

The general underestimation of base flow is partially a result of using the Nash-Sutcliffe efficiency as the objective function, which attributes more weight to high flows. On the other hand, it may also be that the interdependency of the groundwater reservoir and the river channel gives rise to underestimation of base flow. The interaction between the saturated domain and the river domain is governed by Darcian flow, which is linear: $e_{s r} \propto K_{s r} \cdot \Delta h$, where $\Delta h$ is the head difference between the saturated domain and the river domain. During dry periods, the head difference is positive and drives water flow towards the river as base flow whereas during large storm events, it can become negative so that water flows towards the saturated zone as bank infiltration. In the calibration mode, the baseflow parameter $K_{s r}$ may be ad- justed to optimise the high flow performance of the model and in so doing it may reduce the base flow performance. One possible way of improving low flow simulation would be to decouple this two-way interaction or to define different $K_{s}$ values for low flow and high flow, respectively. The latter is potentially promising because the hydraulics of bank infiltration is essentially different from groundwater exfiltration. Additionally we could follow a stepped calibration approach where the $K_{s r}$ during low flows is determined by the Nash-Sutcliffe objective function using the logarithm of discharge $(Q)$ after which it is fixed during subsequent high flow calibration.

Modelling results indicate that subsurface storm flow contributes considerably to runoff generation of the catchment, however, no data is as yet available to verify the modelling details in this particular aspect. Field experiments with appropriate tracer technology may help to investigate the runoff composition, thus assisting in scrutinising the model. The model deals with subsurface storm flow assuming that the topography is a control of the flow rate. The average slope of the catchment is applied to represent the topography effect. This application implies that subsurface topography is parallel to surface topography. As Freer et al. (2002) demonstrated that local bedrock topography can play a significant role in subsurface storm flow formation, this assumption remains to 
Areal rainfall in the Hesperange catchment

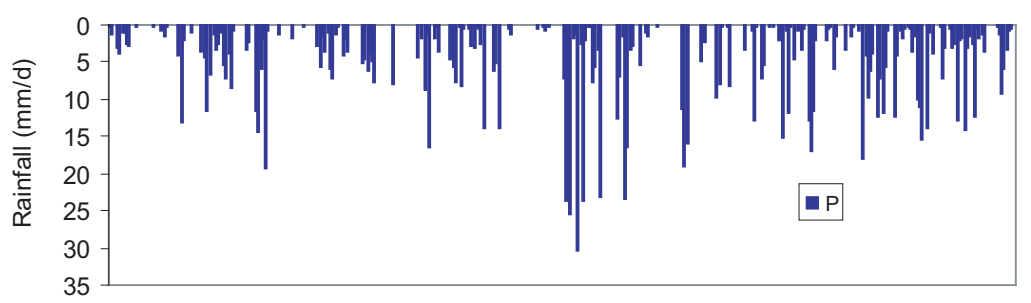

Comparison of the observed and simulated

groundwater dynamics(The Dumontshaff gauging station vs. REW 10)

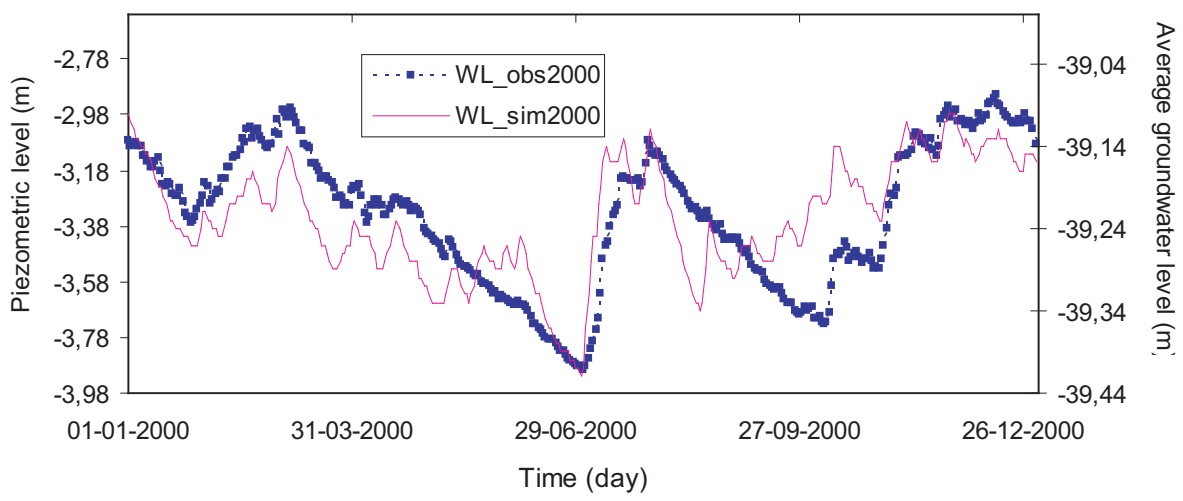

Fig. 14. Comparison of the observed and the simulated groundwater dynamics of the sub-catchment REW 10 (1 January $2000-31$ December 2000).

be tested. Heterogeneity of the macropore system below the REW scale is ignored, while it can be taken into account at above REW scale. Tackling the slope heterogeneity at subREW scale is difficult and one could argue that it is against the original REW concept. Nevertheless, the model provides a general framework for further study. In this research, storm flow in the macropore domain is described as a flux exchange without taking routing effect into account. Given the fast response characteristics of the study catchment, this simplification is justifiable. When transferring this model to elsewhere, relaxation of this simplification may be needed. The introduction of the macropore domain increases the complexity of the model, giving rise to a higher equifinality problem. Therefore, uncertainty and parameter identifiability analysis would be an important task for follow-up research.

Correct mapping of the saturation-excess overland flow area is crucial for a process-based model applied to saturation-prone regions. This part of a catchment is the basis for translating rain falling on it into runoff sustaining the rapid rise of storm peaks. It appears that the model requires a high percentage (23\%-47\% for each of the REWs, respectively) of the catchment area to be saturated all year round. Compared to what field studies reported, this ratio seems high. For instance, field observations in other regions, as presented by Freeze (1974), Tanaka et al. (1988), Güntner et al. (1999), and Srinivasan et al. (2002), among others, show that the extent of the saturated fraction of the catchments is usually less than $10 \%$ during storm events. In our modelling results, however, we observed that the range of the effective area fraction for producing hydrograph peaks of each REW, varies between $3 \%$ and $8 \%$ (see e.g. Fig. 8), which is well in agreement with the research quoted above. We interpret the persistently high ratio of the total saturated area as an integral representation of the really saturated and near saturated area, indicating that this part of the area is readily available for initialising surface runoff. The relatively high value of the saturated area fraction is most probably a consequence of the implicit topographic simplification of the REW approach.

It appears, from model evaluation using the stream flow data measured at internal gauging stations, that the model is less efficient for REWs with a larger size and steeper slope (e.g., REW 12). However, one should realise that the difference between the simulated and the observed discharge may also be due to the fact that the station is located upstream the REW outlet. Nevertheless, we see that the model, even with its lumped structure, is well capable of capturing the hydrological signature of the catchment. To gain more insight into this issue, we propose an alternative modelling strategy whereby the model is first calibrated on the internal gauging data with respect to the corresponding REWs, and subsequently extended to the whole catchment for verification. 
It is realised that a process-based model can only be successful if it represents the real world processes. In the REW approach, system states are always average values. Therefore, the states that are closely linked to geometric quantities (e.g. groundwater level to elevation) may not be accurately modelled by the REW approach in absolute terms. However, it is expected that the dynamic pattern of the states can be modelled accurately. It is also expected that for REWs with small variations in elevation (and other properties), better simulations can be obtained, compared to those REWs that have a higher degree of heterogeneity. This is substantiated by simulations of the groundwater level. The pattern of groundwater table dynamics, indicated by piezometer levels, was well represented by the simulated groundwater levels of the REWs (Fig. 12 to Fig. 14). It is observed that the groundwater table dynamics was best simulated for the low lying watershed, REW 5, which has a smaller surface gradient. The connection between slope and the capacity to correctly simulate groundwater dynamics is an interesting topic for future study. Such knowledge would help to better understand the model behaviour and provide more plausible interpretation of results. It also has the potential that such knowledge can be transferred to ungauged basins.

It is noted that the model's response to input is stronger than the real world catchment, indicated by a stronger fluctuation of the simulated groundwater levels. This is likely due to the fact that the natural threshold behaviour of the catchment, which is strongly affected by the subsurface spatial heterogeneity, and the effects of subsurface flow routing are not fully represented by the model. Another important issue is that the effect of the spatial variability of rainfall over the catchment is not sufficiently considered in the model. This, in addition to the spatial averaging of the approach, which forces the model to react to the events in a linear way, attributes to the model inefficiency with respect to the groundwater simulation. In general, the model shows a linear behaviour, which can be explained by one or more of the fluxes entering the groundwater reservoir. These fluxes are infiltration, percolation and macropore recharge. The latter is described by a linear relationship. The infiltration flux is expressed in a nonlinear format (Eq. 8), but it is found that the unsaturated depth $\left(y_{u}\right)$ is mostly dominant, leading to an approximately linear flux. The percolation flux is also nonlinear, however, in the course of our analysis, we found out that this flux has a limited effect on groundwater dynamics. As a result, infiltration and macropore recharge have the largest impact on groundwater table variations. Consequently, we may have to reconsider the linearity of macropore recharge. This confirms the importance of finding appropriate closure relations for the REW approach, which has been stressed in most of the recent publications concerning the REW approach (Reggiani and Schellekens, 2003; Lee et al., 2005; Zhang and Savenije, 2005).

\section{Summary and conclusions}

In this research, the Representative Elementary Watershed (REW) approach has been further developed by the inclusion of a new process domain, the macropore flow domain, in which subsurface storm flow is simulated. As a result, the mass balance equations of the REW approach have been revised and a set of closure relations for the newly introduced fluxes associated with the macropore flow process have been developed. The flow processes related to the macropore domain are infiltration, lateral quick flow and preferential recharge. The infiltration flux is split into two parts of which one flows into the soil matrix and the other into the macropore domain. The partitioning is determined by the infiltration capacity. The closure relations proposed for the lateral flux and the preferential recharge flux suggest that macropore flow depends on soil properties and is topographically controlled.

Hence, the model code REWASH has been revised and applied to the Hesperange catchment of the Alzette River Basin. This catchment is characterised by quick response to precipitation. Subsurface flow is one of the dominant runoff generation processes. Model simulations have been carried out using 4 years of rainfall and potential evaporation data. The model has been evaluated using a multi-criteria method with discharge data measured at the catchment outlet, at various interior gauging stations, and piezometric measurements distributed over the catchment. The results show that subsurface storm flow makes a significant contribution to stream flow in the headwater sub-catchments; the active saturation overland flow area fraction simulated for each sub-catchment falls well in the range of saturated area by field mapping reported in the literature; the groundwater table dynamics are well represented by the model. This research suggests that the model is able to predict stream flow and groundwater dynamics and is a useful tool for catchment scale hydrological analysis.

Acknowledgements. This research has been funded partly by the Delft Cluster project Oppervlaktewater hydrologie: 06.03.04 and partly by the Delft Cluster project Veiligheid tegen overstromingen: CT04.30. The authors thank D. P. Solomatine of UNESCO-IHE for providing the GLOBE optimisation software for automatic calibration. We acknowledge P. Reggiani for kindly providing the original computer code, the basis of which the numerical model REWASH has been developed. Comments of referees and the editor contributed to great improvement of the manuscript.

Edited by: E. Zehe

\section{References}

Beckers, J. and Alila, Y.: A model of rapid preferential hillslope runoff contributions to peak flow generation in a temperate rain forest watershed, Water Resour. Res., 40, W03501, doi:10.1029/2003WR002582, 2004. 
Beven, K. J.: Searching for the Holy Grail of scientific hydrology: $Q_{t}=(S, R, \Delta t) A$ as closure, Hydrol. Earth Syst. Sci., 10, 609618, 2006, http://www.hydrol-earth-syst-sci.net/10/609/2006/.

Beven, K. J. and Germann, P. F.: Water flow in soil macropores II: a combined flow model, J. Soil Sci., 32, 15-29, 1981.

Beven, K. J. and Germann, P. F.: Macropores and water flow in soils, Water Resour. Res., 18, 1311-1325, 1982.

Bishop, K., Seibert, J., Köhler, S., and Laudon, H.: Resolving the double paradox of rapid mobilized old water with highly variable responses in runoff chemistry, Hydrol. Processes, 18, 185-189, 2004.

Brooks, R. H. and Corey, A. T.: Hydraulic properties of porous media, Hydrol. Pap. No. 3, Colorado State Univ., Fort Collins, 1964.

Christiansen, J. S., Thorsen, M., Clausen, T., Hansen, S., and Refsgaard, J. C.: Modelling of macropore flow and transport processes at catchment scale, J. Hydrol., 299, 136-158, 2004.

Downer, C. W. and Ogden, F. L.: Prediction of runoff and soil moistures at the watershed scale: Effects of model complexity and parameter assignment, Water Resour. Res., 39(3), 1045, doi:10.1029/2002WR001439, 2003.

Freer, J., McDonnell, J. J., Beven, K. J., Peters, N. E., Burns, D. A., Hooper, R. P., Aulenbach, B., and Kendall, C.: The role of bedrock topography on subsurface storm flow, Water Resour. Res., 38, 1269, doi:10.1029/2001WR000872, 2002.

Freeze, A. R.: Streamflow generation, Rev. Geophys. Space Phys., 12, 627-647, 1974.

Güntner, A., Uhlenbrook, S., Seibert, J., and Leibundgut, Ch.: Multi-criterial validation of TOPMODEL in a mountainous catchment, Hydrol. Processes, 13, 1603-1620, 1999.

Hamon, W. R.: Estimating potential evapotranspiration, J. Hydraulics Div. Proc. Am Soc. Civil Eng., 87, 107-120, 1961.

Hewlett, J. D. and Hibbert, A. R.: Factors affecting the response of small watersheds to precipitation in humid areas, in: Proceedings of 1st International Symposium on Forest Hydrology, edited by: Sopper, W. E. and Lull, H. W., Pergamon, pp. 275-290, 1967.

Jarvis, N.: The MACRO Model (Version 4.3): Technical Description, http://www.mv.slu.se/bgf/macrohtm/macro.htm, last updated 23 September 2004.

Lee, H., Sivapalan, M., and Zehe, E.: Representative Elementary Watershed (REW) approach, a new blueprint for distributed hydrologic modelling at the catchment scale: development of closure relations, in: Predicting ungauged streamflow in the Mackenzie river basin: today's techniques \& tomorrow's solutions, edited by: Spence, C., Pomeroy, J. W., and Pietroniro, A., Canadian Water Resources Association (CWRA), Ottawa, Canada, pp. 165-218, 2005.

Lee, H., Zehe, E., and Sivapalan, M.: Predictions of rainfall runoff and soil moisture dynamics in a microscale catchment using the CREW model, Hydrol. Earth Syst. Sci. Discuss., 3, 1667-1743, 2006, http://www.hydrol-earth-syst-sci-discuss.net/3/1667/2006/.

Ludwig, R., Gerke, H. H., and Wendroth, O.: Describing water flow in macroporous field soils using the modified macro model, $\mathrm{J}$. Hydrol., 215, 135-152, 1999.

Nash, J. E. and Sutcliffe, J. V.: River flow forecasting through conceptual models, Part I: a discussion of principles, J. Hydrol., 10, 282-290, 1970
Madsen, H.: Parameter estimation in distributed hydrological catchment modelling using automatic calibration with multiple objectives, Adv. Water Resour., 26, 205-216, 2003.

McDonnell, J. J.: The rationale for old water discharge through macropores in a steep, humid catchment, Water Resour. Res., 26, 2821-2832, 1990

McDonnell, J. J.: Where does water go when it rains? Moving beyond the variable source area concept of rainfall-runoff response, Hydrol. Processes, 17, 1869-1875, 2003.

Mosely, M. P. and Mckerchar ,A. I.: Streamflow, in: Handbook of Hydrology, edited by: Maidment, D. R., McGraw-Hill, NY, USA, pp. 8.1-8.39, 1993.

Niehoff, D., Fritscha, U., and Bronstert, A.: Land-use impacts on storm runoff generation: scenarios of land-use change and simulation of hydrological response in a meso-scale catchment in SW-Germany, J. Hydrol., 267, 80-93, 2002.

Pfister, L. and Hoffmann, L.: Experimental hydro-climatological atlas of the Alzette river basin, Grand-duchy of Luxembourg, Centre de Recherche Public - Gabriel Lippmann, Luxembourg, Grand-duchy of Luxembourg , ISBN-2919900048, 2002.

Refsgaard, J. C.: Parameterisation, calibration and validation of distributed hydrological models, J. Hydrol., 198, 69-97, 1997.

Refsgaard, J. C. and Storm, B.: MIKE SHE, in: Computer models of watershed hydrology, edited by: Singh V. P., Water Resources Publications, USA, pp. 809-846, 1995.

Reggiani, P. and Schellekens, J.: Modelling of hydrological responses: the representative elementary watershed approach as an alternative blueprint for watershed modelling, Hydrol. Process., 17, 3785-3789, 2003.

Reggiani, P. and Rientjes, T. H. M.: Flux parameterization in the Representative Elementary Watershed (REW) Approach: application to a natural basin, Water Resour. Res., 41, W04013, doi:10.1029/2004WR003693, 2005.

Reggiani, P., Sivapalan M., and Hassanizadeh, S. M.: A unifying framework of watershed thermodynamics: balance equations for mass, momentum, energy and entropy and the second law of thermodynamics, Adv. Water Res., 22, 367-368, 1998.

Reggiani, P., Sivapalan, M., and Hassanizadeh, S. M.: Conservation equations governing hillslope responses: Physical basis of water balance, Water Resour. Res., 38, 1845-1863, 2000.

Reggiani, P., Hassanizadeh, S. M., Sivapalan, M., and Gray, W. G.: A unifying framework of watershed thermodynamics: Constitutive relationships, Adv. Water Res., 23, 15-39, 1999.

Reggiani, P., Sivapalan, M., Hassanizadeh, S. M., and Gray, W. G.: Coupled equations for mass and momentum balance in a stream network: theoretical derivation and computational experiments, Proc. R. Soc. Lond., A(2001), 457, 157-189, 2001.

Scanlon, T. M., Raffensperger, J. P., Hornbergern, G. M., and Clapp, R. B.: Shallow subsurface storm flow in a forested headwater catchment: Observations and modeling using a modified TOPMODEL, Water Resour. Res., 36(9), 2575-2586, doi:10.1029/2000WR900125, 2000.

Sidle, R. C., Tsuboyama, Y., Noguchi, S., Hosoda, I., Fujieda, M., and Shimizu, T.: Stormflow generation in steep forested headwaters: a linked hydrogeomorphic paradigm, Hydrol. Process., 14, 369-385, 2000.

Sidle, R. C., Noguchi, S., Tsuboyama, Y., and Laursen, K.: A conceptual model of preferential flow systems in forested hillslopes: evidence of self-organization, Hydrol. Processes, 15 , 
1675-1692, 2001.

Sivapalan, M.: Process complexity at hillslope scale, process simplicity at the watershed scale: is there a connection?, Hydrol. Processes, 17, 1037-1041, 2003.

Sklash, M. G. and Farvolden, R. N.: The role of groundwater in storm runoff, J. Hydrol., 43, 45-65, 1979.

Solomatine D. P.: Genetic and other global optimization algorithms - comparison and use in calibration problems, in: Proceedings of the 3rd International Conference on Hydroinformatics, Copenhagen, Denmark, Balkema Publishers, pp. 1021-1028, 1998.

Solomatine, D. P.: The use of global random search methods for models calibration, in: Proceedings of XXVIth Congress of the International Association for Hydraulic Research (IAHR), vol. 1, London, pp. 224-229, 1995.

Sorooshian, S., Duan, Q., and Gupta, V. K.: Calibration of rainfallrunoff models: Application of global optimization to the Sacramento Soil Moisture Accounting Model, Water Resour. Res., 29, 1185-1194, 1993.

Srinivasan, M. S., Gburek, W. J., and Hamlett, J. M.: Dynamics of stormflow generation - A hillslope-scale field study in eastcentral Pennsylvania, USA, Hydrol. Processes, 16, 649-665, 2002.

Tanaka, T., Yasuhara, M., Sakai, H., and Marui, A.: The Hachioji experimental basin study-storm runoff processes and the mechanism of its generation, J. Hydrol., 102, 139-164, 1988.

Tarboton, D. G.: A new method for the determination of flow directions and contributing areas in grid digital elevation models, Water Resour. Res., 33, 309-319, 1997.

Uchida, T., Kosugi, K., and Mizuyama, T.: Effects of pipe flow and bedrock groundwater on runoff generation in a steep headwater catchment in Ashiu, central Japan, Water Resour. Res., 38(7), 1119, doi:10.1029/2001WR000261, 2002.

Uhlenbrook, S., Frey, M., Leibundgut, C., and Maloszwski, P.: Hydrograph separations in a mesoscale mountainous basin at event and seasonal timescales, Water Resour. Res., 38(6), 1096, doi:10.1029/2001WR000938, 2002.
Whipkey, R. Z.: Subsurface stormflow from forested slopes, Bull. Int. Assoc. Sci. Hydrol., 10, 74-85, 1965.

Wigmosta, M. S. and Burges, S. J.: An adaptive modeling and monitoring approach to describe the hydrologic behaviour of small catchments, J. Hydrol., 202, 48-77, 1997.

Williams, A. G., Dowd, J. F., and Meyles, E. W.: A new interpretation of kinematic stormflow generation, Hydrol. Process., 16, 2791-2803, 2002.

Zehe, E., Maurer, T., Ihringer, J., and Plate, E.: Modeling water flow and Mass Transport in a Loess Catchment, Phys. Chem. Earth (B), 26, 487-507, 2001.

Zehe, E. and Blöschl, G.: Predictability of hydrologic response at the plot and catchment scales: role of initial conditions, Water Resour. Res., 40, W10202, doi:10.1029/2003WR002869, 2004.

Zhang, G. P. and Savenije, H. H. G.: Rainfall-runoff modelling in a catchment with a complex groundwater flow system: application of the Representative Elementary Watershed (REW) approach, Hydrol. Earth Syst. Sci., 9, 243-261, 2005, http://www.hydrol-earth-syst-sci.net/9/243/2005/.

Zhang, G. P., Fenicia, F., Rientjes, T. H. M., Reggiani, P., and Savenije, H. H. G.: Modeling runoff generation in the Geer River Basin with improved model parameterizations to the REW approach, Phys. Chem. Earth, 30, 285-296, 2005 a.

Zhang, G. P., Savenije, H. H. G., Fenicia, F., Rientjes, T. H. M., and Reggiani, P.: Implications of hydrological modelling and observations in the Alzette river basin, in: Proceedings of NCR-days 2004: Research for managing rivers: present and future issues, edited by: Makaske, B. and van Os, A. G., NCR publication 262005, Netherlands Centre for River Studies, Delft, The Netherlands, pp. 74-76, 2005 b. 